\title{
Global trends in visibility: implications for dust sources
}

\author{
N. M. Mahowald ${ }^{1}$, J. A. Ballantine ${ }^{2,}$, J. Feddema ${ }^{3}$, and N. Ramankutty ${ }^{4}$ \\ ${ }^{1}$ National Center for Atmospheric Research, Boulder Colorado, USA \\ ${ }^{2}$ Institute for Computational Earth System Science, University of California, Santa Barbara, CA, USA \\ ${ }^{3}$ Department of Geography, University Kansas, Lawrence, Kansas, USA \\ ${ }^{4}$ Department of Geography, McGill University, Montreal, Quebec, Canada \\ *now at: United States Geological Survey, Denver, Colorado, USA
}

Received: 8 January 2007 - Published in Atmos. Chem. Phys. Discuss.: 27 February 2007

Revised: 23 May 2007 - Accepted: 15 June 2007 - Published: 26 June 2007

\begin{abstract}
There is a large uncertainty in the relative roles of human land use, climate change and carbon dioxide fertilization in changing desert dust source strength over the past 100 years, and the overall sign of human impacts on dust is not known. We used visibility data from meteorological stations in dusty regions to assess the anthropogenic impact on long term trends in desert dust emissions. We did this by looking at time series of visibility derived variables and their correlations with precipitation, drought, winds, land use and grazing. Visibility data are available at thousands of stations globally from 1900 to the present, but we focused on 357 stations with more than 30 years of data in regions where mineral aerosols play a dominant role in visibility observations. We evaluated the 1974 to 2003 time period because most of these stations have reliable records only during this time. We first evaluated the visibility data against AERONET aerosol optical depth data, and found that only in dusty regions are the two moderately correlated. Correlation coefficients between visibility-derived variables and AERONET optical depths indicate a moderate correlation (0.47), consistent with capturing about $20 \%$ of the variability in optical depths. Two visibility-derived variables appear to compare the best with AERONET observations: the fraction of observations with visibility less than $5 \mathrm{~km}$ (VIS5) and the surface extinction (EXT). Regional trends show that in many dusty places, VIS5 and EXT are statistically significantly correlated with the Palmer drought severity index (based on precipitation and temperature) or surface wind speeds, consistent with dust temporal variability being largely driven by meteorology. This is especially true for North African and Chinese dust sources, but less true in the Middle East, Australia or South America, where there are not consistent patterns in the correlations. Climate indices such as El Nino or the North Atlantic Oscillation are not correlated with
\end{abstract}

Correspondence to: N. M. Mahowald

(mahowald@ucar.edu) visibility-derived variables in this analysis. There are few stations where visibility measures are correlated with cultivation or grazing estimates on a temporal basis, although this may be a function of the very coarse temporal resolution of the land use datasets. On the other hand, spatial analysis of the visibility data suggests that natural topographic lows are not correlated with VIS5 or EXT, but land use is correlated at a moderate level. This analysis is consistent with land use being important in some regions, but meteorology driving interannual variability during 1974-2003.

\section{Introduction}

Mineral aerosols or desert dust particles are hypothesized to be important for local health and air quality problems, as well as impacts on the global environment through changes in the radiative budget, precipitation processes, atmospheric chemistry and biogeochemistry (e.g. Rosenfeld and Nirel, 1996; Dentener et al., 1996; Miller and Tegen, 1998; DeMott et al., 2003; Jickells et al., 2005). While mineral aerosol sources are thought to be dominated by natural processes (e.g. Prospero et al., 2002), the possibility of human impacts on mineral aerosols cannot be eliminated by the existing data (Mahowald and Dufresne, 2004; Tegen et al., 2004; Mahowald et al., 2004; Mahowald et al., 2005). On small scales, cultivation or pasture usage has been shown to increase the availability of particles for wind erosion (e.g. Gillette, 1988; Neff et al., 2005). In addition, ice core records show that dust is sensitive to climate change (e.g. Petit et al., 1999). Thus, human influenced climate change and land use may be impacting dust concentrations. Finally, plants are thought to be better able to deal with water stress under a higher carbon dioxide environment, suggesting that desert extent (and presumably therefore dust) may be decreasing over the last century as carbon dioxide levels increase (e.g. Smith et al., 2000; Mahowald and Luo, 2003). Attempts to determine the impacts

Published by Copernicus Publications on behalf of the European Geosciences Union. 
of global scale anthropogenic land use on dust emissions are hampered by the similarity in the spatial distribution of land use derived dust and natural dust for some sources (e.g. Mahowald et al., 2002, 2004; Luo et al., 2003). Results of modeling simulations suggest that humans have either increased or decreased dust since preindustrial times, depending on the relative importance of human land use, carbon dioxide fertilization and climate change in driving dust (Mahowald and Luo, 2003). Ice core changes between the preindustrial and current time periods are not consistent within regions and cannot differentiate between these different processes (Mahowald and Luo, 2003).

One long time series that is globally available is visibility data collected at meteorological stations. It has been used in many previous studies (e.g. Middleton, 1984; McTainsh et al., 1989; Goudie and Middleton, 1992; Sun et al., 2001). However, visibility data have not been compiled and presented globally with time trends in previous studies. These data are available at hourly to several times daily intervals over much of the last century at many meteorological stations located throughout the world. One problem with these data is that visibility is not directly related to aerosol concentration, but may be influenced by humidity, cloudiness or rain. Visibility is a function of the amount of light which is attenuated as a viewer looks horizontally, and if the attentuation is due to aerosols, it is the extinction of light by aerosols occuring at the surface of the earth (surface extinction). In addition, aerosol amount near a station may be impacted by very local effects, such as the existence of a dirt road directly in front of the observer (e.g. Middleton et al., 1985). Another drawback of the visibility data is that while there are hundreds of stations, they are located close to human habitation, which tends not to be in the middle of deserts. Traditionally researchers have considered visibility as too qualititavely to be compared against models or other data. In this paper we try to address how quantitatively we can use the visibility data, and especially whether it represents very local dust or dust capable of being transported long range. Thus as a first step in our analysis, we compared the visibility data against other high quality aerosol data (AERONET aerosol optical depths: Holben et al., 2001) to understand the quantitative value of this dataset. Our goal in the first part of the paper is to determine whether visibility data can be used to evaluate dustiness, and what relationship the visibility data has to surface source variability.

Many processes may be important for the generation of atmospheric dust, including strong winds, precipitation, drought conditions, land surface properties, and human land use. For each of these processes we try to derive a representative proxy from a global dataset to correlate with the visibility dataset. However, this approach has fundamental limitations due to lack of quality data. There is a large spatial variability in surface winds and precipitation, making these variables difficult to constrain globally (e.g. Dai et al., 1996). Very little is known globally about land surface properties, and we address these in a future study. Especially problematic are datasets on the time evolution of human cultivation and grazing. The datasets used here present a broad view of the time evolution of cultivation and grazing, and represent the best datasets available (Klein-Goldewijk, 2001; Ramankutty and Foley, 1999). However they are interpolations between land use censuses taken every 5 years in the best case, and often every 10 years or longer, and therefore crudely represent the time record of human land use. In addition, it is not clear how human land use would impact dust. Some studies have shown that cultivation and grazing make soils much easier to deflate (Gillette, 1988; Neff et al., 2005). Soil conservation efforts such as trees planted to block the winds, contour plowing, and leaving dead vegetation on the top of the soils have been shown to be effective in reducing wind erosion (e.g. Baker et al., 2005). Thus, it is not always straightforward to deduce what the relationship should be between human land use and dust. This paper may provide some information about where land use may be enhancing dust sources.

Our goal in this paper is to use visibility data for estimating long term trends in aerosols, especially desert dust aerosols. We describe our methods in Sect. 2. We first evaluate several proxies derived from the hourly visibility data against AERONET column aerosol optical depth data in Sect. 3. Then we use visibility proxies to look at temporal trends in dusty regions. Finally, we correlate visibility proxies with meteorological variables such as precipitation and wind speeds as well as the human driven variables, estimated cultivation and grazing use (Sect. 4). Summary and conclusions are presented in Sect. 5.

\section{Methodology}

For this paper, we analyze hourly to several times daily station data from the DSS 463.3 surface weather observation dataset created by the National Climatic Data Center (NCDC) and archived at NCAR (http://dss.ucar.edu/datasets/ ds463.3/). This data set contains up to 10000 active stations worldwide. We analyze this dataset over the period 19002003 for long term trends in visibility. For the bulk of the analyses, we include stations with data in at least 30 years of the period from 1900-2003. In dusty regions, where most of our analysis takes place, there are no data before 1940, so we do not focus on that time period. Indeed, there are substantially more data from 1974-2003, so we concentrate much of our correlation analysis on that time period, discussing only briefly results for the longer time period.

Visibility data from these sites are in meters, and indicate how far away a large black object can be seen against the sky at the horizon (Seinfeld and Pandis, 1998). Detailed descriptions of measurement methods at different stations and their evolution with time are not available. The dataset includes quality checks, and data which do not pass all quality checks 
are neglected here. We also visually inspect the different station time series to look for discontinuities in the data, specifically in the wind data, and rejected 7 stations due to this problem (WMO stations 400720, 400830, 400870, 607600 612970847820 and 854170). In addition, we exclude any data when the dew point temperature is within one degree Celsius of the temperature to attempt to exclude fog events. There are over one thousand stations with data for at least 30 years, but only 364 stations with more than 30 years of data in dusty regions (we discuss the reasons for focussing on dusty regions in Sect. 2.0).

In order to evaluate the visibility measurements, we compare them against data from AERONET sun photometry stations, which are in situ column optical depth measurements (Holben et al., 2001) (http://aeronet.gsfc.nasa.gov/ data_menu.html). Because we are interested in variability in visibility, we only use the data from AERONET stations with more than 3 years of data, and we calculate the correlation coefficient between monthly mean aerosol optical depth at $670 \mathrm{~nm}$ and monthly visibility proxies at the closest meteorological stations. We chose this wavelength because it appears to have the most data, and varies in a manner similar to other visible wavelengths in the same dataset (not shown).

We evaluate several different visibility proxies at the AERONET sites. The fraction of observations when the visibility is less than 1,5 , or $10 \mathrm{~km}$ has been used previously (e.g. N'Tchayi Mbourou et al., 1997; Kurosaki and Mikami, 2003). We evaluate the fraction of visibility below a succession of thresholds between 1 and $10 \mathrm{~km}$ to determine which best reproduces the column aerosol optical depth from AERONET. In addition, visibility is really a measure of the integrated surface concentration of aerosols and other particles between the eye and distant objects, and can be converted to a surface extinction value (aerosol extinction of light when a viewer is looking horizontally at the surface) through Koschmeider's formula (Godish, 1997):

Extinction $=3.92 /$ Visibility

Thus for each month, we calculate the fraction of measurements where the visibility is below $\mathrm{x} \mathrm{km}$ (where $\mathrm{x}$ goes from 1 to $10 \mathrm{~km}$ ) and the monthly mean surface extinction.

Previous studies have used data from the Total Ozone Mapping Spectrometer Absorbing Aerosol Index (AAI) and the Aerosol Optical Depth (AOD) (Torres et al., 1998, 2002) for deducing information about dust spatial+ and temporal variability (e.g. Prospero et al., 2002; Mahowald et al., 2003), so here we compare them against the AERONET optical depths to better understand how good the AAI does at measuring aerosol optical depth. The TOMS AAI uses the absorption of Rayleigh backscattered uv light to deduce absorbing aerosols, which has the trait of giving a response that is roughly linear with aerosol height (Mahowald and Dufresne, 2004; Torres et al., 1998), and giving a response that is different in sign depending on the type of aerosol (Torres et al., 1998). In order to deduce a more easily interpreted aerosol optical depth, TOMS AAI are combined with atmospheric transport and radiation model output to produce a TOMS AOD (Torres et al., 2002). However, in both datasets there are difficulties with interpreting the long time series, because of problems in changes in the satellite and drift in the orbits: the time period from 1984 to 1990 is the most stable (O. Torres, personal communication; Torres et al., 2002).

Also included in the station data are surface wind speeds. Unfortunately, the height at which these measurements are made is not the same at all stations, or may change with time in a way which is not well documented. Further, surface wind speeds can be very sensitive to nearby structures, which may evolve with time. As with the visibility data, surface wind speed data should not be taken at face value over such a large spatial area and long time series. However, the data represents our only information about local surface wind speeds at many stations over a long period of time, so we include them here. Any station where the surface wind speeds changed in a discontinuous manner (detected by visual inspection) was excluded from the analysis, as described above. Wind data were analyzed to determine the median wind, as well as the average of the cubed of individual wind observations.

Precipitation data from a merging of two gridded monthly time series from Chen et al. (2002) and Dai et al. (1997), as described in Dai et al. (2004) are used. Precipitation data are also difficult to interpret because of the hetereogeneities in the spatial distribution of precipitation. However, this gridded dataset represents our best state of knowledge about precipitation at the global scale. From gridded historical temperature and precipitation datasets, Palmer Drought Severity Index (PDSI) values were calculated and included in this analysis (Dai et al., 2004). This index tries to capture the cumulative departure from the mean of atmospheric moisture and soil moisture supply at the surface, based on a simple hydrological model. It incorporates antecedent precipitation, moisture supply and moisture demand based on simple hydrological model. The results of correlations with PDSI and visibilty tended to be larger in magnitude than between precipitation and visibility, so we focus on only the PDSI results in this paper. We also use two climate indices that have been developed in previous studies: the El Nino 3.4 (ENSO; Trenberth and Stepaniak, 2001) and the North Atlantic Oscillation (NAO; Hurrell, 1995).

We also include estimates of human influences on visibility and desert dust specifically. Estimates of human land use practices are difficult to make, especially in desert regions. We used half degree resolution datasets based on cropland area estimates from (Ramankutty and Foley, 1999) and grazing extent from the HYDE database (Klein-Goldewijk, 2001). The cultivation and grazing data were combined with satellite derived estimates of Plant Functional Type distributions. The grazing data were calibrated to match the extent of present day grass and shrub distributions and then extrapolated back in time based on the HYDE historical grazing es- 
timates at the half degree grid scale (Feddema et al., 2007 ${ }^{1}$ ).

For most of the analysis here, we use simple correlation coefficients. In order to calculate statistical significance we need to assume that our distributions are gaussian, which may not be true. We make these assumptions so that our results are easy to interpret. We have calculated these correlations using rank correlations, for which we know the ranked distribution, and obtain qualitatively similar results (not shown). We also test to see whether one of our variables uniquely captures variability, or if there are mulitple variables which might explain a certain time variability. We do this by conducting a multiple linear regression, and evaluating how much variability our model captures with all variables, and then with all variables minus the one we are interested in. If the difference in variability explained is substantially different (we arbitrarily chose $>25 \%$ ), then we consider that this variable is "irreplaceable" by another variable. The "irreplaceable" variables by this criteria are plotted with an extra square on the correlation plots that follow. Note that for most of the correlations in this paper, there is not just one variable which might be responsible, so this adds to the difficulty in interpreting the results of these analyses. We do this analysis based on annual averages, but qualitatively similar results are found if we use instead monthy means.

In order to determine regions where mineral aerosols are the dominant aerosol in terms of surface extinction, we use the results of the Rasch et al. (2001) model simulations. These simulations are based on 3-dimensional transport modeling using the Model of Atmospheric Transport and Chemistry (Rasch et al., 1997) driven by the National Center for Environmental Prediction/National Center for Atmospheric Research (NCEP/NCAR) reanalysis wind dataset (Mahowald et al., 1997; Kistler et al., 2001). Sources for different aerosols follow (Rasch et al., 2001) and the simulations are for 1995-2000. The mineral aerosol source model in these simulations is based on the Dust Entrainment and Deposition model (Zender et al., 2003a), as implemented and evaluated by (Mahowald et al., 2002, 2003b; Luo et al., 2003). The model uses a friction wind velocity cubed relationship to determine the sources, and a preferential source defined by Ginoux et al. (2001), which assumes that natural topographic lows (representing dry lake beds) are dust sources. The model includes simple sulfur chemistry and sulfate aerosols, black and organic carbon aerosols, and sea salt aerosols, as described in more detail in Rasch et al. (2001). These aerosol sources include anthropogenic and natural sources, including biomass burning (see papers for more details). We use this model for analysis that elucidates the theoretical relationship between dust sources and extinction, and where dust dominates the aerosol loading, as discussed in more detail in Sects. 3 and 4. In the real world,

\footnotetext{
${ }^{1}$ Feddema, J., Lawrence, P., Bauer, J., and Jackson, T.: A global land cover dataset for use in transient climate simulations, JAMC, submitted, 2007.
}

we do not have data directly measuring dust source fluxes, so that we will use a model to estimate the relationship between dust source fluxes and downwind concentrations and column amounts. This result will be biased if the model has incorrect representation of vertical or horizontal transport.

\section{Evaluation of visibility data}

Before using the visibility data to understand global trends, we first analyze the visibility data to estimate the quality of the data for determining aerosol distributions. As indicated in the introduction, low visibility events could indicate high mineral aerosols, high total aerosols, fog or rain events. These visibility events, even if due to aerosols, could be very local, e.g. due to a dirt road next to the meteorological station, or due to long range transported aerosols. There are markers in the datasets that specifically indicate dust events or rain events, but these markers are not always there, so it was not possible to use these to screen all the data consistently. It is possible that the visibility data represents very small scale aerosol events (less than $1 \mathrm{~km}$ ) that are not representative of large scale dust transport. At stations where visibility is dominated by these small events, the visibility record would presumably not be well correlated with the AERONET aerosol optical depth. In addition, we look at how well visibility (or suface extinction) is able to capture variability in dust fluxes and compare to other available datasets, such as satellite derived optical depth.

\subsection{Visibility data as a measure of aerosol optical depth}

To assess the ability of visibility measurements to capture dust variability on longer time scales we use aerosol optical depth measurements. Aerosol optical depth is measured at many sites globally using sun photometers and recorded in the AERONET dataset (Holben et al., 2000; http://aeronet.gsfc.nasa.gov/data_frame.html), which has high quality aerosol optical depth data for the last few years. For this study, we are interested in variability, so we use the stations where there are more than 3 years of data (33 stations, listed in Table 1; locations shown in Fig. 1). Notice that there are significantly fewer AERONET stations than visibility stations and their data extend over a shorter time period, which is why we are focusing on the visibility data for this paper. In order to compare to visibility data, we chose the closest visibility station location which has 3 years of overlaping data with the monthly mean AERONET data. The visibility station used for comparison with the AERONET data may not necessarily have a long record or be included in the main analysis (shown in Fig. 1). Notice that in all but three cases, the visibility station is close to the AERONET site (much less than 1 degree away, as seen in Fig. 1). The exceptions are Abracos Hill, where the closest station is 2.5 degrees away, and Dry Tortugas and the HJ An- 
Table 1. Monthly mean AERONET aerosol optical depth vs. monthly mean surface extinction at closest meteorological station.

\begin{tabular}{|c|c|c|c|c|c|c|c|c|}
\hline $\begin{array}{l}\text { AERONET } \\
\text { station }\end{array}$ & $\begin{array}{l}\text { visibility } \\
\text { station }\end{array}$ & Lat.(N) & Lon. (E) & \# Mo & $\begin{array}{l}\text { Obs. Corr. } \\
\text { Ext vs. } \\
\text { AOD }\end{array}$ & $\begin{array}{l}\text { Model Corr. } \\
\text { Ext. vs. } \\
\text { AOD }\end{array}$ & $\begin{array}{l}\text { Model Frac. } \\
\text { Surf.Ext. } \\
\text { From Dust }\end{array}$ & \\
\hline Abracos Hill & 828240 & -10.8 & -62.3 & 49 & 0.70 & 0.95 & 0.04 & \\
\hline Alta Floresta & 829650 & -9.9 & -56.0 & 65 & 0.70 & 0.93 & 0.03 & \\
\hline Arica & 854060 & -18.5 & -70.3 & 59 & NS & 0.88 & 0.61 & $*$ \\
\hline Ascension Island & 619020 & -7.9 & -14.4 & 49 & NS & 0.33 & 0.07 & \\
\hline Avignon & 075860 & 43.9 & 4.9 & 49 & NS & 0.87 & 0.12 & \\
\hline Banizoumbou & 610520 & 13.5 & 2.7 & 65 & 0.44 & 0.69 & 0.86 & $* *$ \\
\hline Bondville & 725315 & 40.1 & -88.3 & 80 & NS & 0.82 & 0.01 & \\
\hline Capo Verde & 085940 & 16.7 & -22.9 & 94 & NS & 0.13 & 0.66 & $* *$ \\
\hline Cart Site & 723536 & 36.5 & -97.5 & 63 & NS & 0.92 & 0.09 & \\
\hline Cove, Virginia & 723075 & 36.9 & -75.8 & 51 & NS & 0.56 & 0.01 & \\
\hline Dalanzadgad & 443730 & 43.5 & 104.4 & 76 & 0.30 & 0.92 & 0.73 & $* *$ \\
\hline Dry Tortugas & 722010 & 24.5 & -82.9 & 48 & NS & 0.44 & 0.11 & \\
\hline El Arenosillo & 084490 & 37.1 & -6.8 & 36 & NS & 0.88 & 0.29 & \\
\hline Goddard SFC & 745940 & 39.0 & -76.8 & 126 & NS & 0.87 & 0.01 & \\
\hline HJAndrews AFB & 726930 & 44.2 & -122.2 & 60 & NS & 0.73 & 0.03 & \\
\hline Ispra & 160660 & 45.7 & 8.6 & 70 & NS & 0.82 & 0.09 & \\
\hline Kanpur & 423690 & 26.4 & 80.3 & 36 & NS & 0.95 & 0.34 & \\
\hline Lanai & 911905 & 20.7 & -156.9 & 63 & NS & 0.64 & 0.03 & \\
\hline Maricopa & 722749 & 33.1 & -112.0 & 42 & NS & 0.97 & 0.13 & \\
\hline Mauna Loa & 911977 & 19.5 & -155.5 & 99 & NS & 0.41 & 0.03 & \\
\hline Maryland SC & 724060 & 39.2 & -76.6 & 52 & NS & 0.80 & 0.01 & \\
\hline Mexico City & 766800 & 19.3 & -99.2 & 43 & NS & 0.79 & 0.04 & \\
\hline Mongu & 676330 & -15.3 & 23.1 & 48 & 0.69 & 0.37 & 0.07 & \\
\hline Nes Ziona & 401800 & 31.9 & 34.8 & 43 & 0.50 & 0.82 & 0.54 & $* *$ \\
\hline Ouagadougou & 644030 & 12.2 & -1.3 & 58 & 0.32 & 0.71 & 0.80 & $* *$ \\
\hline Rimrock & 727830 & 46.5 & -116.9 & 43 & NS & 0.87 & 0.05 & \\
\hline Rogers Dry Lake & 723810 & 34.9 & -117.9 & 48 & NS & 0.92 & 0.04 & \\
\hline Sede Boker & 401910 & 30.8 & 34.8 & 74 & NS & 0.81 & 0.54 & $* *$ \\
\hline Sevilleta & 723650 & 34.3 & -106.9 & 103 & NS & 0.97 & 0.12 & \\
\hline Skukuza & 682650 & -24.9 & 31.5 & 65 & NS & 0.72 & 0.05 & \\
\hline Solar Village & 404370 & 24.9 & 46.4 & 53 & 0.59 & 0.86 & 0.82 & $* *$ \\
\hline Venise & 161050 & 45.3 & 12.5 & 55 & NS & 0.90 & 0.08 & \\
\hline Wallops & 724020 & 37.9 & -75.5 & 55 & 0.36 & 0.87 & 0.01 & \\
\hline
\end{tabular}

NS indicates the correlation is not significant at the $99 \%$.

* indicates that dust dominates other aerosols in the surface extinction and are included in the next Table.

indicates that dust dominates other aerosols, but that fog is likely, so the station is omitted.

drews Air Force Base, where the closest visibility station is 1 degree away from the AERONET site.

For this paper we assume that the visibility data are of such a poor quality that it cannot be used as a proxy for dustiness until it has been verified that it shows aerosols seen in other reliable data. This is a different assumption than used in other studies, where the fraction of $<1 \mathrm{~km}$ visibilty is assumed to be a reflection of dustiness (e.g. Kurosaki and Mikami, 2003). We think that until the data collection methods have much higher quality control, the measurement methods are better documented and an evaluation of the data occurs in the literature, we will not believe that visibility data contain quantatively interpretable value. Since that information is not available, we are comparing the visibility data to data of known quality to better understand if the visibility data can be interpreted quantatively. Our goal is to understand what fraction of the visibility data can be interpreted as aerosols that are not just important at a very small scale, but important at a scale of $100+\mathrm{km}$.

We correlate the monthly mean aerosol optical depth (AOD) at $670 \mathrm{~nm}$ to the monthly mean surface extinction and the fraction of observations where the visibility is below 1$10 \mathrm{~km}$ threshold at the nearest meteorological stations for all 33 AERONET sites individually. If we removed the seasonal cycle, the correlations would be even lower than described here. In addition, we correlate the values collectively from 


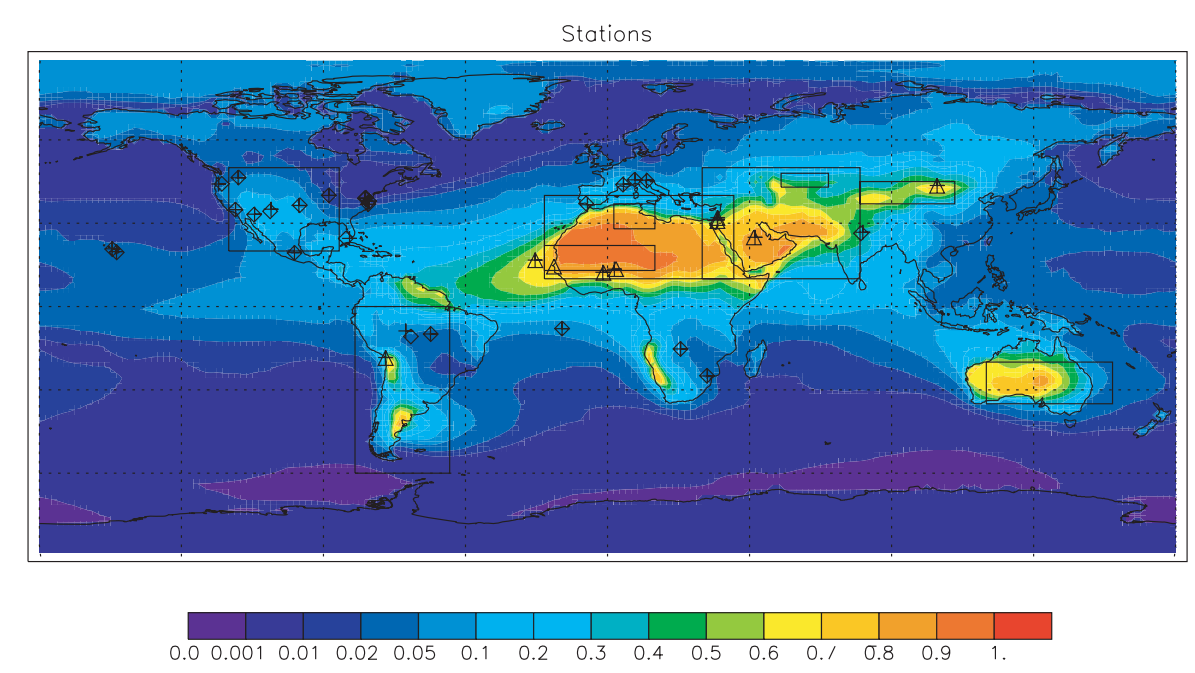

Fig. 1. Location of AERONET stations used in this analysis (diamonds and triangles). Triangles indicate stations where the surface extinction is dominated by dust, while diamonds are stations where other aerosols dominate $(>50 \%)$ model predicted surface extinction (shown as colored contours), using the model of Rasch et al. (2001). Also shown are boxes outlining the different regions emphasized in the main text and following figures.

all the 33 stations across all time, which we will refer to as across all stations. This allows us to compare the visibilityderived variables over as large of a range of values as possible. For most of the surface meteorological stations there is not a statistically significant correlation between AOD and any of the visibility-derived variables (e.g. Table 1, using the example of extinction). These low correlations could be because surface extinction and column extinction (equivalent to AOD) are decoupled in these areas. The low correlations may be because of strong boundary layer inversions as an example. To test this hypothesis, we use model simulations (described in the methodology section) to correlate surface extinction and AOD in a model with the dominant aerosol types. The model suggests that at the locations in this comparison, and over most of the globe, the surface extinction and AOD should be correlated at much higher levels than our results from the data (Fig. 2f and Table 1). Our model is a global model, so we could be missing small scale variability that causes lower correlations in the data. In order to test for this possibility, we correlate the AERONET optical depths from two nearby AERONET stations (Maryland Science Center vs. GSFC, see Table 1 for locations) with each other and we obtain a correlation coefficient of 0.99 suggesting that small scale variability in AOD is not likely to be causing all the discrepancy between the visibility data and column optical depth data in our variability comparisons. This suggests that neither surface extinction derived from the visibility data nor the fraction of observations with less than $1-10 \mathrm{~km}$ visibility are good indicators of regional aerosol optical depth at all stations. There are many possible explanations: the poor quality of the data; moisture impacts on the visibility through clouds; local dust sources (for example a dirt road directly in front of the observer). On the other hand, this lack of correlation could also be that there are elevated aerosol layers which are not seen by the visibility measurer, but being observed by the AERONET data. At this point, we do not know which of these explanations are correct. Note that if we perform the correlation between monthly mean aerosol optical depth from AERONET and data from the visibility stations over all the stations, we obtain correlation coefficients of 0.30 and 0.34 for extinction and fraction of observations with visiblity less than $5 \mathrm{~km}$, respectively. We can obtain higher correlations across all stations using the fraction of observations less than $10 \mathrm{~km}(0.57)$, but this visibility-derived variable still has the high occurrence of non-statistically significant correlations at most stations, similar to that seen in Table 2 for extinction.

There are some stations with a moderate correlation (0.50.7 ) between visibility-derived variables and AOD (Table 1). Many of these stations happen to be in dust regions, and the correlation may be strong because of the dry conditions-e.g. there is no moisture to either cause hydroscopic growth or clouds or moisture itself may reduce visibility. Therefore, we next look specifically at five stations where over $50 \%$ of the surface extinction is predicted by the model to be from mineral aerosols in model simulations (Rasch et al., 2001) (marked with $* *$ in Table 1). In addition, we reject one station (Arica, marked with * in Table 1) on the western coast of South America. Arica has low correlations, probably because of the high frequency of fog and stratus clouds at this location. Using this subset of five AERONET stations and the ten adjacent meteorological stations, statistically significant correlations between the AERONET column optical depth and the visibility-derived variables are 

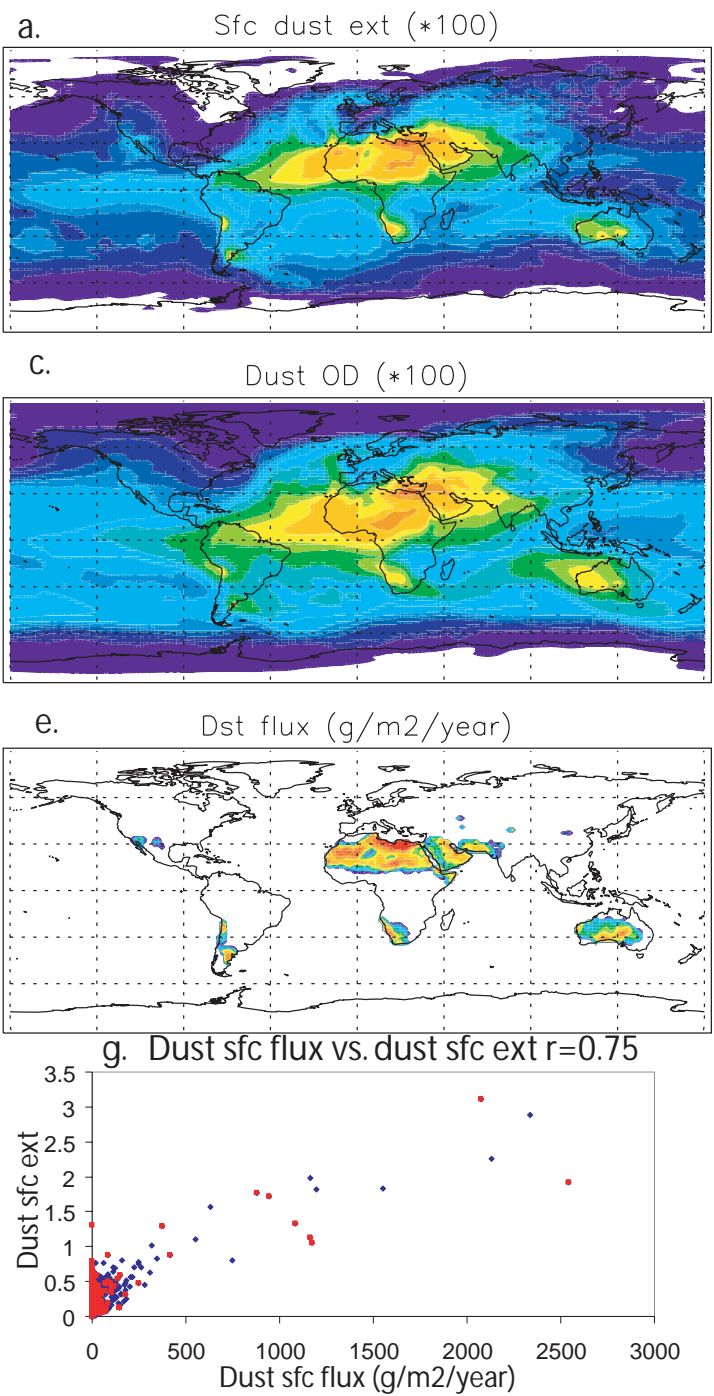

i. Dust sfc flux vs dust OD $r=0.46$

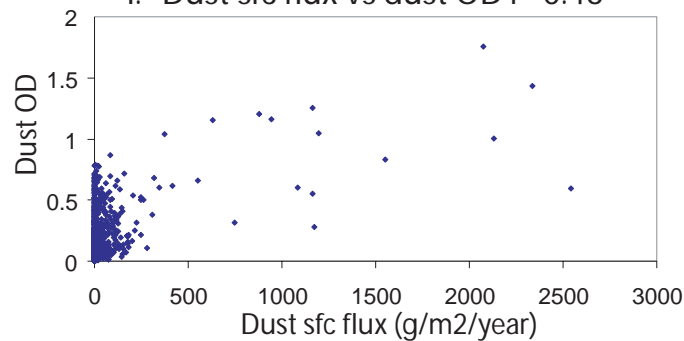

b. Sfc ext (all aerosols) $(* 100)$

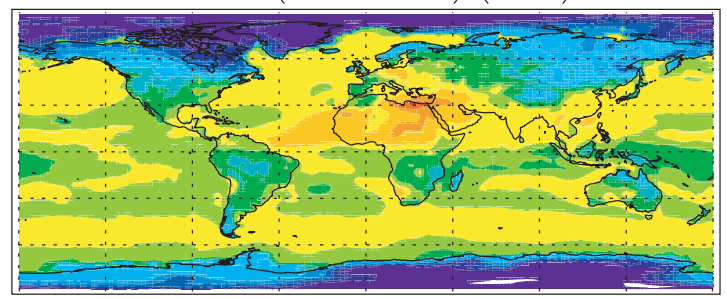

d. Column OD (all aerosols) $(* 100)$
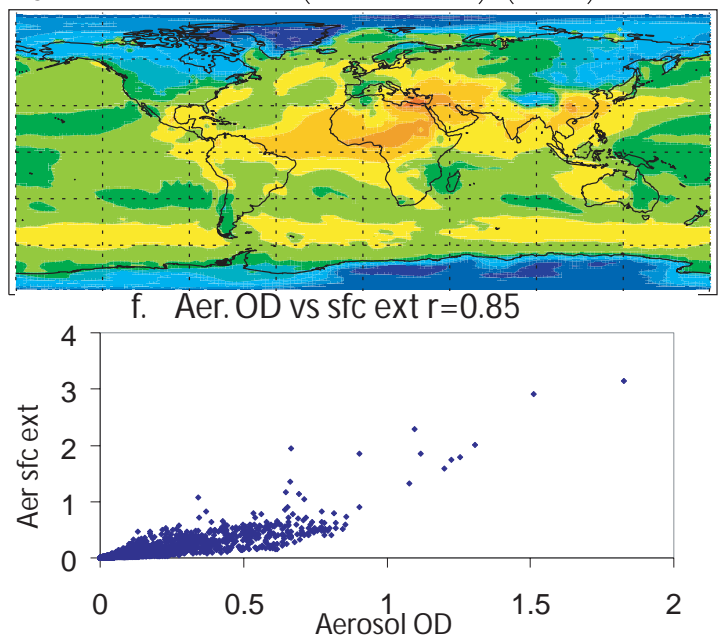

h. Dust sfc flux vs. aer. sfc ext $r=0.69$
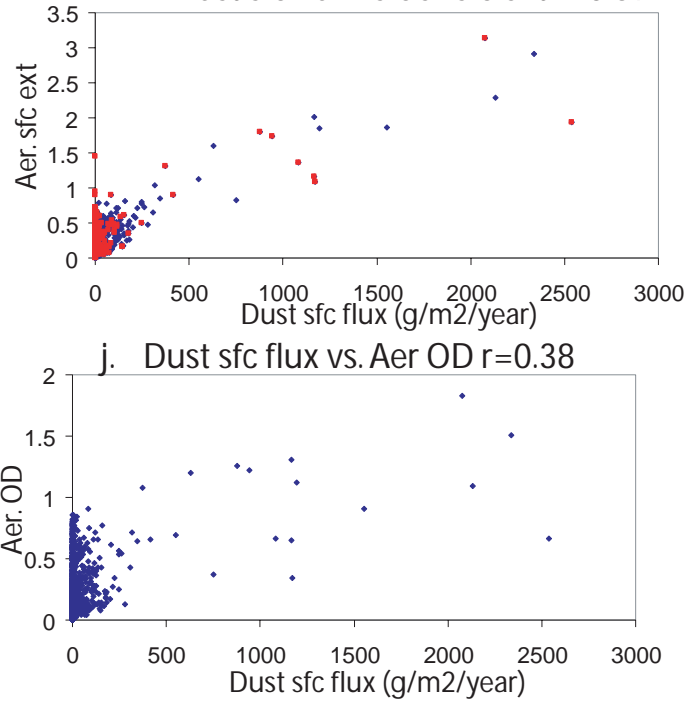

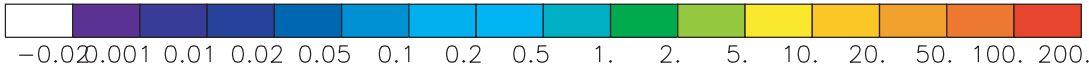

Fig. 2. Spatial plots of monthly mean dust surface extinction (a), total aerosol surface extinction (b), dust column aerosol optical depth (c), total aerosol column optical depth (d) dust source flux (e)), scatter plot of total aerosol optical depth vs. total aerosol surface extinction (f), scatter plot of dust surface flux vs. dust surface extinction in land gridboxes (red boxes are only at the gridboxes which have meteorological stations analyzed in this paper) (g), scatter plot of dust surface flux vs. total aerosol surface extinction in land gridboxes (red boxes are only at the gridboxes which have meteorological stations analyzed in this paper) (h), scatter plot of dust surface fluxes vs. dust aerosol optical depth in land gridboxes (i) and scatter plot of dust surface fluxes vs. total aerosol optical depth in land grid boxes (j). All values are from the model described in the text. 
Table 2. Visibility proxies at dusty stations.

\begin{tabular}{ll}
\hline Visibility variable & $\begin{array}{l}\text { Overall correlation } \\
\text { at dusty stations } \\
\text { (marked with } * * \\
\text { in previous table) }\end{array}$ \\
\hline Extinction & 0.47 \\
Fraction of observations with visibility $<1 \mathrm{~km}$ & 0.23 \\
Fraction of observations with visibility $<2 \mathrm{~km}$ & 0.42 \\
Fraction of observations with visibility $<3 \mathrm{~km}$ & 0.45 \\
Fraction of observations with visibility $<4 \mathrm{~km}$ & 0.47 \\
Fraction of observations with visibility $<5 \mathrm{~km}$ & 0.46 \\
Fraction of observations with visibility $<6 \mathrm{~km}$ & 0.45 \\
Fraction of observations with visibility $<7 \mathrm{~km}$ & 0.47 \\
Fraction of observations with visibility $<8 \mathrm{~km}$ & 0.44 \\
Fraction of observations with visibility $<9 \mathrm{~km}$ & 0.40 \\
Fraction of observations with visibility $<10 \mathrm{~km}$ & 0.28 \\
\hline
\end{tabular}

obtained (Table 2). The overall correlations for extinction and fraction of observations with a visibility $<5 \mathrm{~km}$ are 0.47 and 0.46 , respectively, indicating that about $22 \%$ of the variability in the optical depths are captured in the visibilityderived variables. These correlation coefficients are not particularly high, but using only the visibility at dusty stations, we are focusing on the stations with the highest correlations with aerosol optical depth.

We calculate the correlation with AERONET optical depth using a variety of visibility-derived variables in order to test which ones compare the best. We obtain the best correlations when we use visibility thresholds between $2-9 \mathrm{~km}$, or use the extinction variable (Table 2), so we chose to continue our analysis with the $5 \mathrm{~km}$ threshold (VIS5) and the extinction variable (EXT). Notice that the fraction of events with visibility less than $1 \mathrm{~km}$ does much worse than either of these two visibility proxies, although it has been previously used for dust studies (e.g. Kurosaki and Mikami., 2003). It is not clear why the $5 \mathrm{~km}$ threshold does better than $1 \mathrm{~km}$ thresholds in comparison with aerosol optical depth, but it could be because $1 \mathrm{~km}$ thresholds are more associated with highly localized events such as the location of a dirt road near the meteorological station.

In order to consider how well the visibility data compare to other datasets used for capturing variability, we repeat this analysis using the TOMS AAI and TOMS AOD - datasets with longer time periods than the AERONET data - that have been used to infer dust source variability (e.g. Mahowald et al., 2003a; Zender and Kwon, 2005). Using all AERONET sites, TOMS AAI and TOMS AOD have correlations of 0.65 , 0.23 , respectively, between the monthly mean values and AERONET optical depth. If we look only at dusty regions (again the stations marked with a $* *$ in Table 1) TOMS AAI and TOMS AOD have correlations of 0.66 and 0.70 , respectively. Thus, over dusty regions, TOMS AAI and TOMS
AOD have similar ability to capture variability in optical depths, but over other regions, TOMS AAI does better. This is not expected, since the AOD is constructed to better consider the effects of different aerosols. However, the TOMS AOD is a combination of model and data, and thus may be biased because of the model used to convert from an AAI to an AOD. There still may remain problems with the use of TOMS AAI or AOD because of drifts in the satellites when outside the 1984-1990 period where the AAI is most stable.

\subsection{Theoretical value for inferring dust sources}

Now that we have evaluated the visibility data to indicate how good of a proxy it is for aerosol amount, we next consider what measurement is the best proxy for surface fluxes of dust. Visibility data are actually measures of surface extinction. If this surface extinction comes solely from aerosols (and not from water vapor or clouds) it is linearly proportional to concentration. AOD is a measure of column extinction. Neither of these variables is directly measuring the surface fluxes. Nonetheless, we are using either surface extinction (visibility-derived variables) or AOD (e.g. Prospero et al., 2001) to try to gain information about surface fluxes. Here we test how much of the variability in surface fluxes is measured by variability in either surface extinctions or AOD. This is an example of a problem where model calculations can provide great insight into how to best infer spatial and temporal variability in surface fluxes when we have no direct measurements. When we try to estimate variability in surface dust fluxes based on other measurements, previous model analyses have suggested that dust surface concentration will capture the variability better than dust column amount (Mahowald et al., 2003b). We extend that analysis here to correlate modeled total aerosol (sum of sulphate, carbonaceous, dust and seasalt) AOD with modeled surface dust fluxes. In the real world, we do not have data directly measuring dust source fluxes, so we will use the aforementioned model to estimate the relationship between variables we can measure (surface extinction or column amount) and dust fluxes (Sect. 3.2). Errors in the model formulation of boundary layer mixing or ventilation, or horizontal transport will cause errors in this correlation. In addition, AERONET includes only cloud free days, while we include all days, causing a possible discrepancy. However, no other methods have been postulated to evaluate the ability of different measurements of dust concentration or optical depth to infer information about dust flux spatial or temporal variability.

First we look at the ability of visibility data and satellite data to provide information about the spatial location of dust sources (Fig. 2). Notice that spatially, the maximum in modeled dust sources are located in different places than the modeled maximum in dust aerosol optical depth or surface concentrations (these plots show monthly mean values for January of 1981, but any particular month or annual average will look similar). The surface concentrations visually 


\section{a. Column AOD vs. surface extinction}

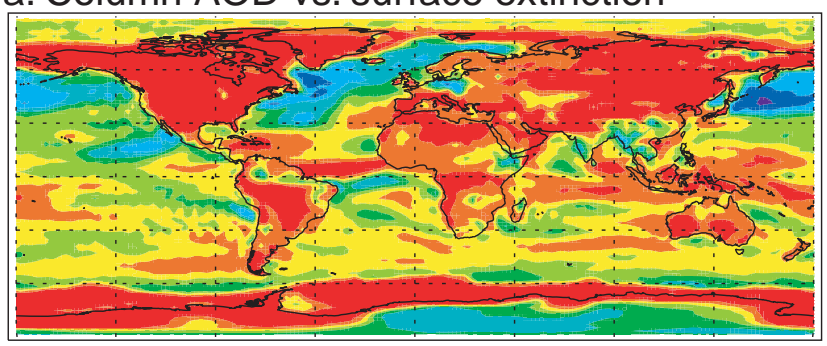

b. Column AOD vs. source flux

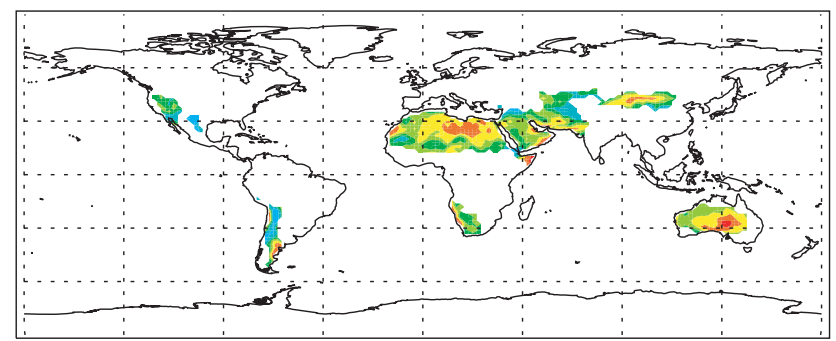

c. Surface extinction vs. source flux.
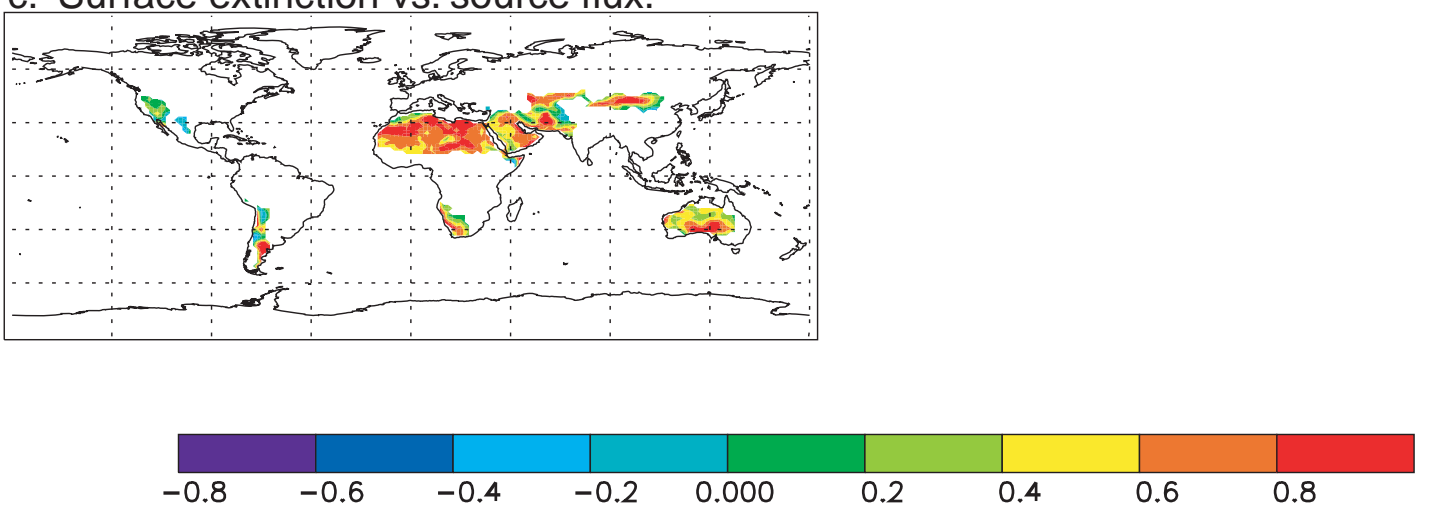

Fig. 3. Correlations of monthly mean modeled column aerosol optical depth (AOD) versus surface extinction (a), AOD vs. surface fluxes (b) and surface extinction vs. surface fluxes (c).

appear more related to surface fluxes than optical depth visually. This is very clear in the scatter plots or the correlation coefficients, which are shown for all land grid points in the model. The correlation coefficients between the spatial locations of dust surface fluxes and surface extinction or optical depth in model are 0.75 and 0.46 , respectively. Since in the real world, we have total aerosol optical depth, not just dust optical depth, that we are using to infer the dust source variability, we can correlate those values instead in a model. Correlating total aerosol and dust surface fluxes results in correlation coefficients of 0.69 and 0.38 , corresponding to capturing $48 \%$ or $14 \%$, respectively, of the spatial variability in dust surface fluxes, when we use surface extinction or optical depths, respectively. In the real world we only have visibility data at a limited number of stations, not globally as we do in the model. If we sample the model output at these stations only, our correlation coefficient between extinction and dust fluxes does not change substantially (0.73). However, this correlation does not include the effect of the low spatial resolution of the visibility data, especially in desert areas. In the real world, TOMS AAI does not sample optical depth, but an aerosol index which is linearly proportional to altitude, making it likely to perform worse at detecting dust source fluxes than the model estimates here. The strength of sources is not well related to the frequency of emissions (Laurent et al., 2005), suggesting that sampling the number of times TOMS AAI is above a certain threshold (e.g. Pros- pero et al., 2002) is not necessarily a better way to obtain information about the sources. (Notice that for our visibilityderived variable, VIS5, which is a frequency variable, does about as well as the EXT variable.) Thus, visibility-derived variables should theoretically do a better job of capturing the spatial variability in dust fluxes than satellite derived optical depth. Whether they practically do is based on their ability to capture regional scale aerosol fluctuations, which is examined in detail in Sect. 3.1.

Next we look at the ability of visibility-derived variables or aerosol optical depth to capture temporal variability of dust source fluxes at individual gridboxes in the model. These results (Figs. 3b and c) show a higher correlation between the monthly mean time series in modeled surface extinction and modeled dust surface fluxes than between modeled AOD and modeled dust surface fluxes. Again, these results suggest that visibility derived variables will do a better job at capturing temporal variability in dust source fluxes than aerosol optical depths. This is only true in practice if the quality of the visibility data in calculating surface extinction is similar to satellite retrieved column amount and has a similar spatial extent. Our analysis suggests that satellite retrieved aerosol optical depths are better than visibility-derived surface extinction at capturing variability at AERONET sites (correlation coefficient of 0.66-0.7 against 0.47). Realize that each of these datasets may be capturing different aspects of the surface flux variability, since they have quite different qualities, and 


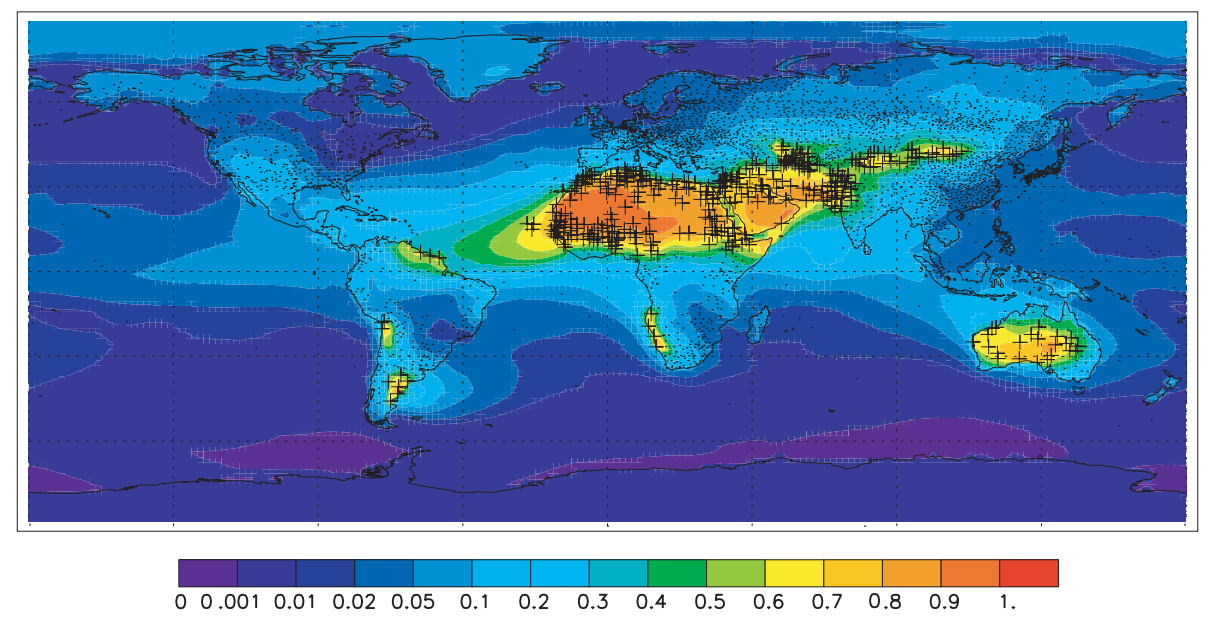

Fig. 4. Location of visibility stations with more than 30 years of data. Colored contours show fraction of surface extinction from desert dust. Pluses show stations in regions dominated by desert dust (>50\%), while dots show other locations.

may be poorly correlated for many reasons that are quite legitimate (e.g. TOMS AAI measures absorbing aerosols, not total aerosols). Although previous studies have implicitly assumed that satellite derived aerosol optical depths provide more information about spatial and temporal variability in dust sources than visibility measurements (e.g. Goudie and Middleton, 2001; Prospero et al., 2002) this analysis does not clearly support that assumption.

\section{Visibility trends and correlations in dust regions}

Since the analysis in Sect. 3 indicates that visibility best correlates with aerosol optical depth in dust dominated regions, we focus on the visibility-derived measures of dust here. Dust dominated regions are defined as those regions where dust contributes to at least $50 \%$ of the surface aerosol extinction in model simulations (Rasch et al., 2001). Figure 4 shows the locations of meteorological stations with at least 30 years of data, and those within our dust dominated region. There are 357 stations from dust dominated regions included in the analysis of the visibility data. We analyze these stations grouped together by region, as well as individually. For this analysis, we focus on annual means and annual mean correlations for simplicity of presentation. Qualitatively similar results were obtained when monthly anomalies were used.

The mean fraction of observations when visibility is less than $5 \mathrm{~km}$ (VIS5) and mean surface extinction (EXT) derived from visibility are shown in Fig. 5 averaged over the period of 1974-2003. If we interpret this map as a proxy for dustiness, it gives us a very different view of where the dust sources are than what we get from TOMS AAI (e.g. Prospero et al., 2002). The Bodele basin does not appear to be the largest source of dust in this region, as some have claimed (e.g. Prospero et al., 2002), and looks quite moderate in this dataset. In our model, which has a strong source of dust in the Bodele basin (seen in Fig. 2b), the model overpredicts the surface extinction downwind of the Bodele basin (relatively speaking-the values can not be compared quantatively), and the visibility stations do appear to be downwind of the Bodele basin plume. One area that stands out in this analysis as having low visibility (high VIS5 and EXT) is the region around Pakistan and India, with low visibility also seen in parts of North Africa, the Middle East and China/Mongolia. We normally do not think of the region near Pakistan and northwestern India as being the largest dust source (e.g. Goudie and Middleton, 2001; Prospero et al., 2002), and the reason this region has such high VIS5 and EXT values could be due to anthropogenic aerosols that may be stronger than our model predicts. On the other hand, Pakistan and northwestern India is generally a highly populated region with an arid climate, and with some of the highest rates of reported desertification (Middleton and Thomas, 1997), so the visibility data could be correct. It is also possible that the visibility data are biased in that a given station could stop reporting data during dust events, biasing where the visibility data suggests the most aerosols are located. There are no stations in North America where dust represents $50 \%$ of the surface extinction, and the stations in South Africa are too few to include for a conclusive analysis. The global distribution of EXT (extinction) and VIS5 (fraction of observations with visibility less than $5 \mathrm{~km}$ ) is different, and this is one of the reasons we analyze both variables. They are equally good (or bad) measures of aerosol optical depth, according to Sect. 3, and yet they are measuring aerosols differently - the number of extreme events (VIS5) compared to background visibility plus extreme events (EXT).

Next we look at each region individually; the bounds on the regional boxes used in the analysis below are shown 

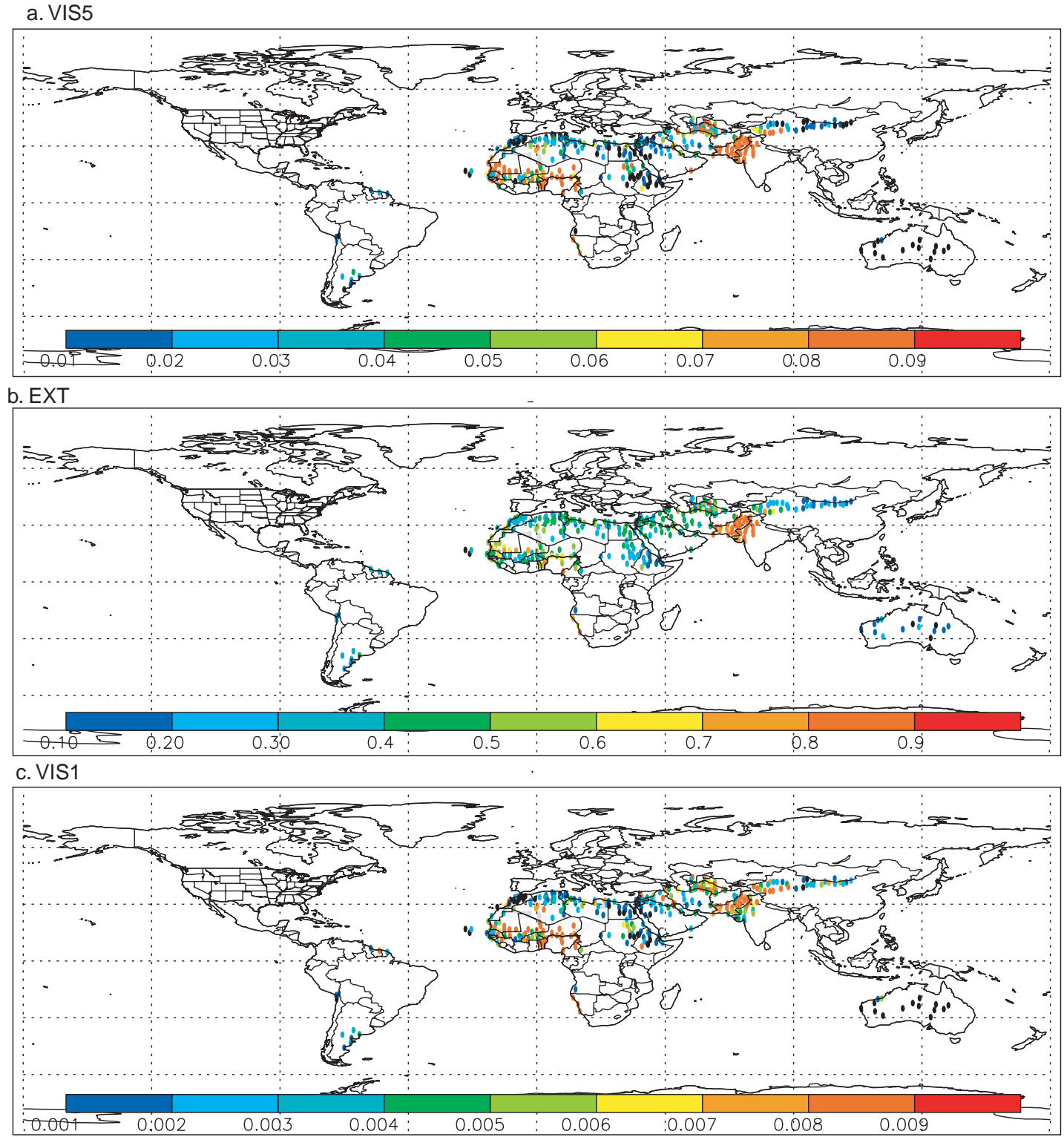

d. Blowing dust or sand

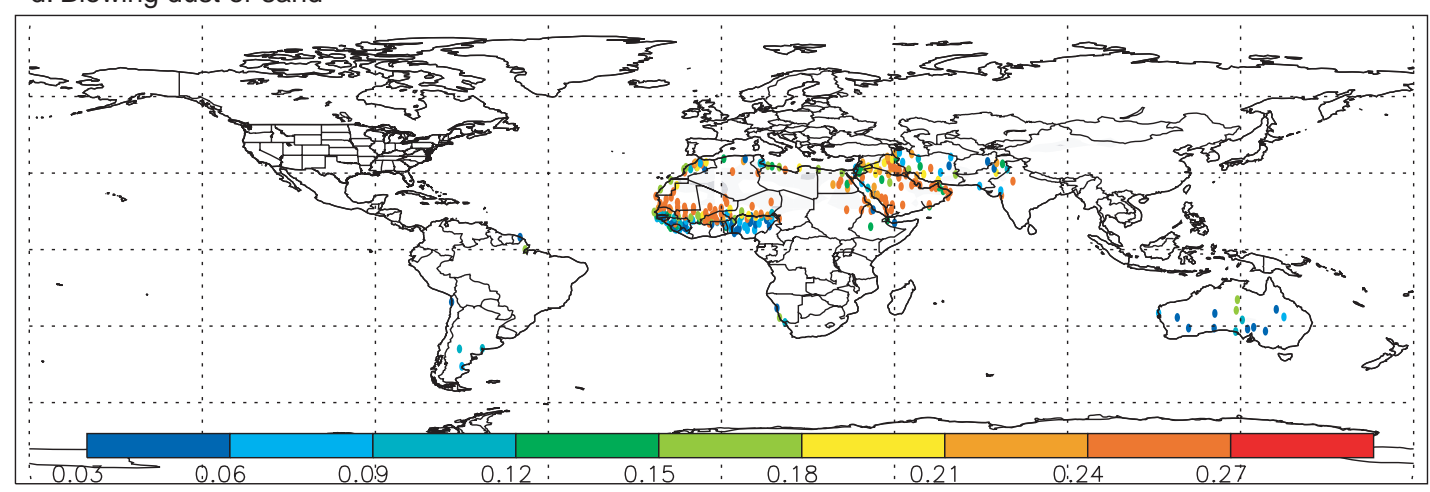

Fig. 5. Mean fraction of visibility $<5 \mathrm{~km}$ (VIS5), mean surface extinction (EXT), and mean fraction of visibility $<1 \mathrm{~km}$ (VIS1) derived from the visibility data averaged over 1974-2003 for each of the areas discussed in the text. Also shown are the dust storm frequency data based on fraction of days with blown dust and sand from Engelstaedter et al. (2003) (d)., divided by 365 days per year. 


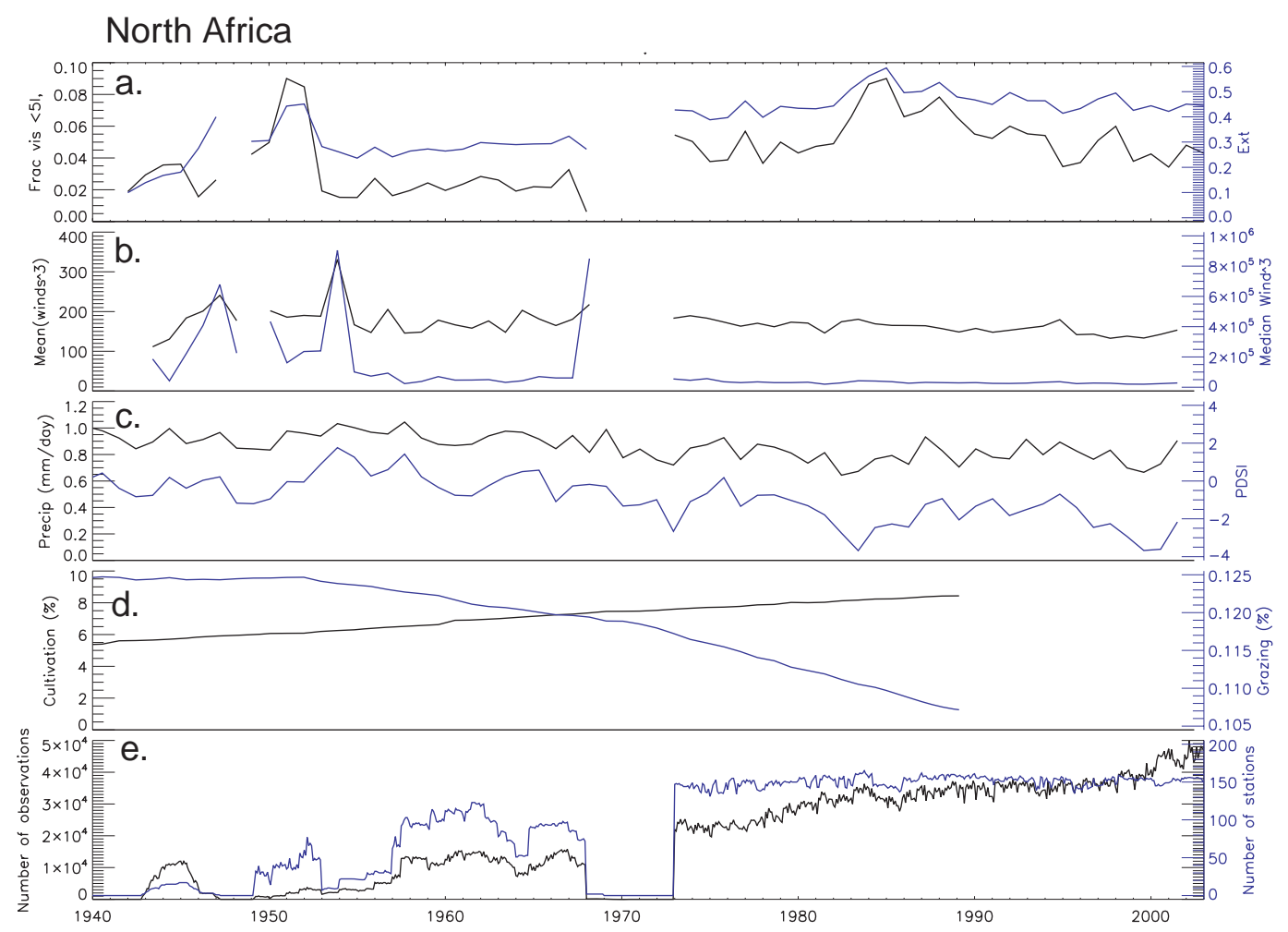

Fig. 6. Time series of the annual average over all the North Africa stations for extinction (EXT), fraction of visibility $<5 \mathrm{~km}$ (VIS5), mean of the cube of the winds, median winds cubed, precipitation, Palmer Drought Severity Index (PDSI), percent of area under cultivation, percent of area under grazing, number of observations and number of stations included in the averages for each year. Figures 1 and 7 show the region over which the stations are averaged. Variable described on the left axis is in black and on the right axis is in blue.

globally in Fig. 1. For North Africa, we show a time series of the average visibility, winds, precipitation, Palmer drought severity index (PDSI) and human land use and grazing in Fig. 6. These values are averaged over the station locations (not over the entire region), to weight them in a manner similar to the visibility. Note that the data at neighboring stations should not be considered statistically independent. Visibility-derived variables (both EXT and VIS5) appear to vary substantially over the time series, even averaged over the whole of North Africa. We can see many visibility events and high extinction during the 1970-1980s, associated with the Sahel drought and higher downwind dust concentrations (e.g. Prospero and Nees, 1986; Prospero and Lamb, 2003). After the 1980s, fractions of VIS5 values decrease by about $50 \%$ while the extinction values decrease more slowly. There is a peak of low visibility during the 1950 s associated with high winds, but the data are quite spotty during the 19401960s. Thus it is not clear how robust these changes are (the standard deviations are large relative to the signals, not shown), although they appear at several different stations (not shown). Precipitation varies over this time period, dominated by the Sahel drought signal, and the Palmer drought severity index (PDSI) is highly correlated with precipitation
(Dai et al., 2004). Cultivation tends to be increasing over this time period, while grazing is decreasing, especially after the 1950s. The poor temporal resolution of observations related to land use is obvious from this figure. Data availability is highly variable over the time period with most consistent observations only available after 1974. This is true in all of dust regions, and because of this we focus our analysis on the period 1974-2003.

We focus next on correlations between these variables at specific stations from 1974-2003 in the North African region. For North Africa, the correlation coefficients between visibility-derived variables and Palmer Drought Severity Index (PDSI), the average of winds cubed, El Nino, NAO, year (indicates where there is a trend in the data), cropland and grazing are shown in Fig. 7. In these plots, reds indicate positive correlations, blues negative correlations, pluses indicate no statistically significant correlations (at 99 percentile significance), and boxes indicate that the correlations only exist between that variable (see methods for how this "irreplaceable" condition is calculated) and the visibility-derived variable. Notice that there are very few correlations which are captured by just one variable, indicating that interpreting the results of the correlation is not staightforward. The strongest 

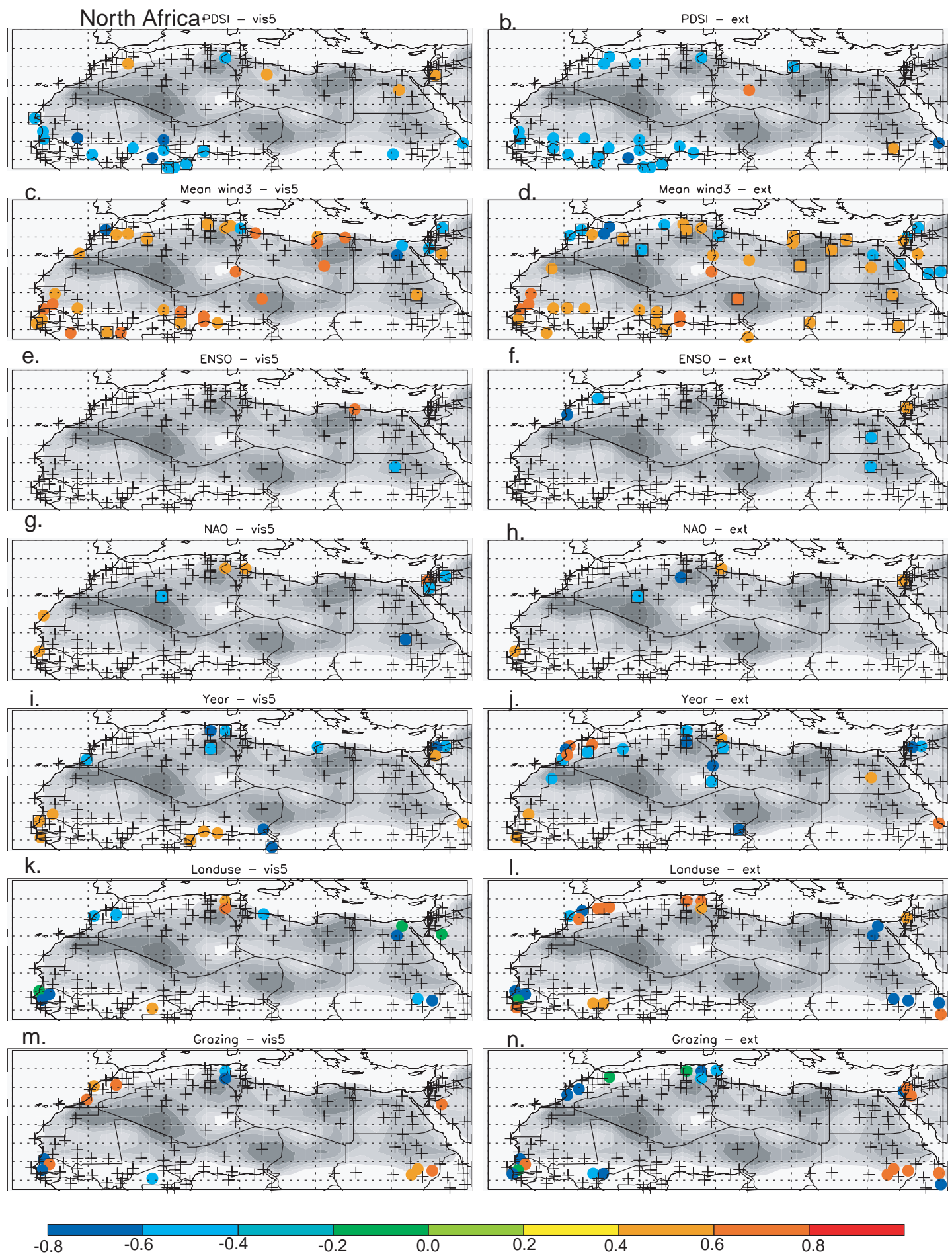

Fig. 7. Correlation coefficient between annual averaged time series of fraction of visibility less than $5 \mathrm{~km}$ (VIS5-left column) and extinction (EXT-right column) for the following variables: Palmer Drought Severity Index (PDSI), mean of the cube of the winds (winds3), El NinoSouthern Oscillation (ENSO), North Atlantic Oscillation (NAO), Year (if correlated, this means there is a trend with time), cropland and grazing. The color bar indicates the correlation coefficient. Boxes around a value indicate the value is irreplaceable (see text for explanation), while pluses indicate not statistically significant. The two variables which are correlated are in the heading of the panel with a hyphen between. The grey scale contours underlying the data represents the dry lake bed factor from Ginoux et al. (2001), for reference to where dust sources from topographic lows should be located. 


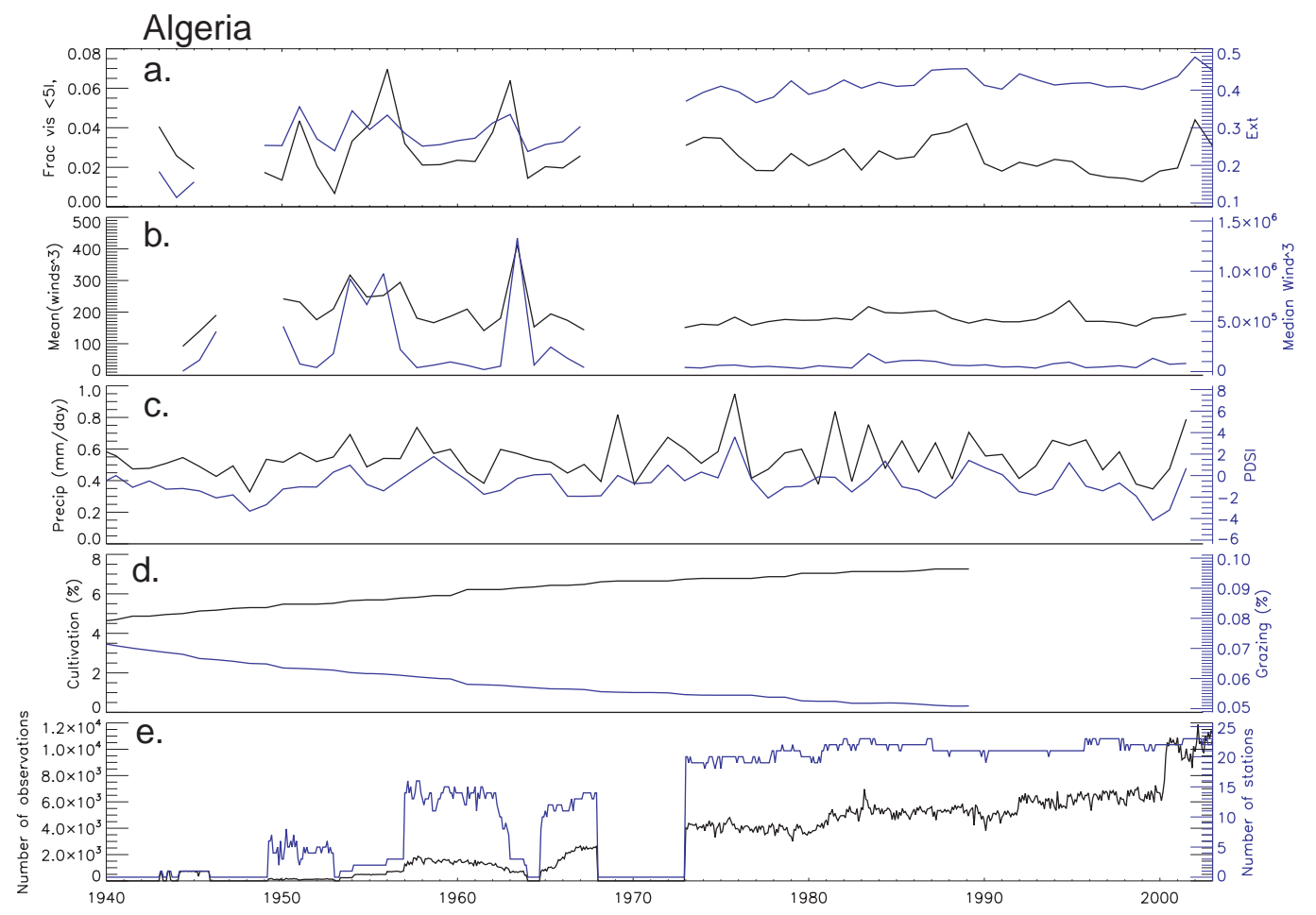

Fig. 8. Same as Fig. 6, but for a region around Algeria (28 N to $3 \mathrm{~N}, 2 \mathrm{E}$ to $15 \mathrm{E}$ and shown in Fig. 1).

correlations are between the PDSI and mean cube of the winds and the VIS5 or EXT variable. We use mean cube of the winds because the strength of dust sources is usually proportional to winds cubed (e.g. Mahowald et al., 2005). This suggests that meteorology drives most of the temporal variability in North Africa, consistent with previous studies (e.g. Prospero and Nees, 1986; N'Tchayi Mbourou et al., 1997; Prospero and Lamb, 2003). The correlations at most stations between PDSI and visibility tend to be larger in magnitude than between precipitation, previous year's precipitation or the previous year's PDSI and visibility (not shown), consistent with drought severity being a better measure of soil moisture than precipitation alone. Thus, we focus on using the PDSI for the rest of the analyses. There is little correlation between ENSO or NAO (Trenberth and Stepaniak, 2001; Hurrell, 1995) and visibility in North Africa (similar to Moulin and Chiapelo, 2004; Chiapelo et al., 2005), unlike further downwind using other datasets (e.g. Moulin et al., 1997; Mahowald et al., 2003b). There are some statistically significant trends in time (i.e. correlations with year) in the VIS5 and EXT, although they are opposite in sign in some cases along the Mediterranean coast of North Africa, indicating that the number of events is going up, but the background aerosol concentration may be going down. If we calculate the correlation over 1940-2003, instead of just over the time period between 1974 and 2003, we obtain much stronger correlations between year and extinction and between land use and extinction along the Mediterranean coast of North Africa, perhaps associated with the difference in the amount of data. Figure 8 shows the average time series in a region centered on Algeria ( $28 \mathrm{~N}$ to $3 \mathrm{~N}, 2 \mathrm{E}$ to $15 \mathrm{E}$ ). This shows that there is little data before 1974, but that the data suggest episodes of high VIS5 and EXT during the 1950s and 1960s. There is a tendency for EXT to be higher later in the century, consistent with a correlation between EXT and year at individual stations (not just because of discontinuities in data records at individual stations). There is also a positive correlation between EXT and cropland and a negative correlation between EXT and grazing (since cropland and grazing are almost linearly increasing and decreasing, respectively, over the 1940-1990s). Similar behaviour is seen for the average of all the stations in the W. Sahel $(13 \mathrm{~N}$ to $22 \mathrm{~N}, 20 \mathrm{~W}$ to 15E) time series (Fig. 9), with a peak in VIS5 and EXT in 1985 (during the Sahel drought), with some high values of VIS5 and EXT in the 1940s and 1950s.

The time series for the Middle East region is shown in Fig. 10. Similar to North Africa, there tend to be many low visibility events in the beginning of the time record (19401960s), where there are few data (and large standard deviations, not shown). But during the 1974-2003 period, when the amount of data is more stable, there is not as much fluctuation in VIS5 or EXT, although mean winds decrease. Correlation coefficients at each individual station over 1974 to 2003 (Fig. 11) suggest that meteorology is not as important 


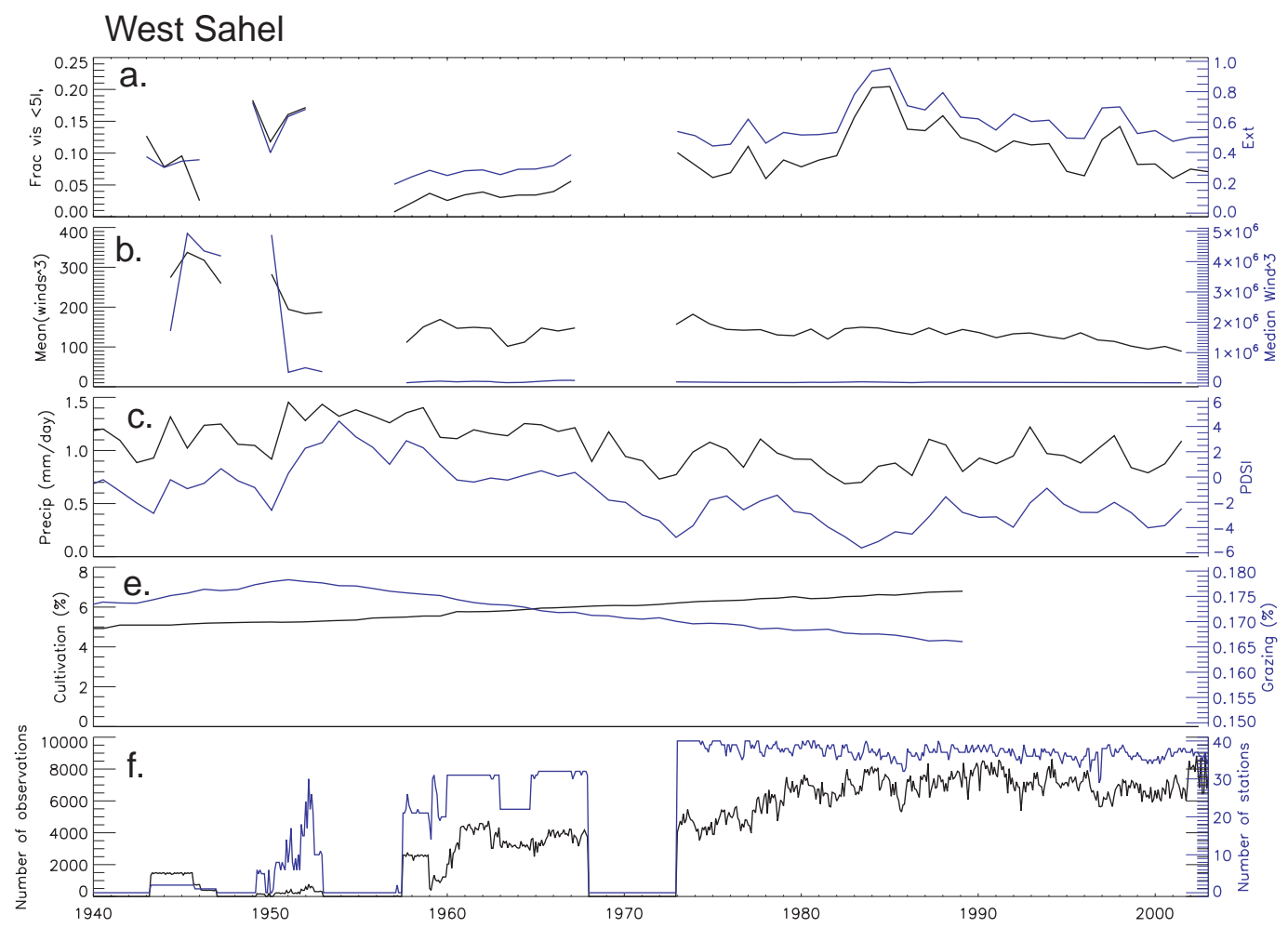

Fig. 9. Same as Fig. 6, but for a region in the Western Sahel (13 N to $22 \mathrm{~N}, 20 \mathrm{~W}$ to $15 \mathrm{E}$ also shown in Fig. 1).

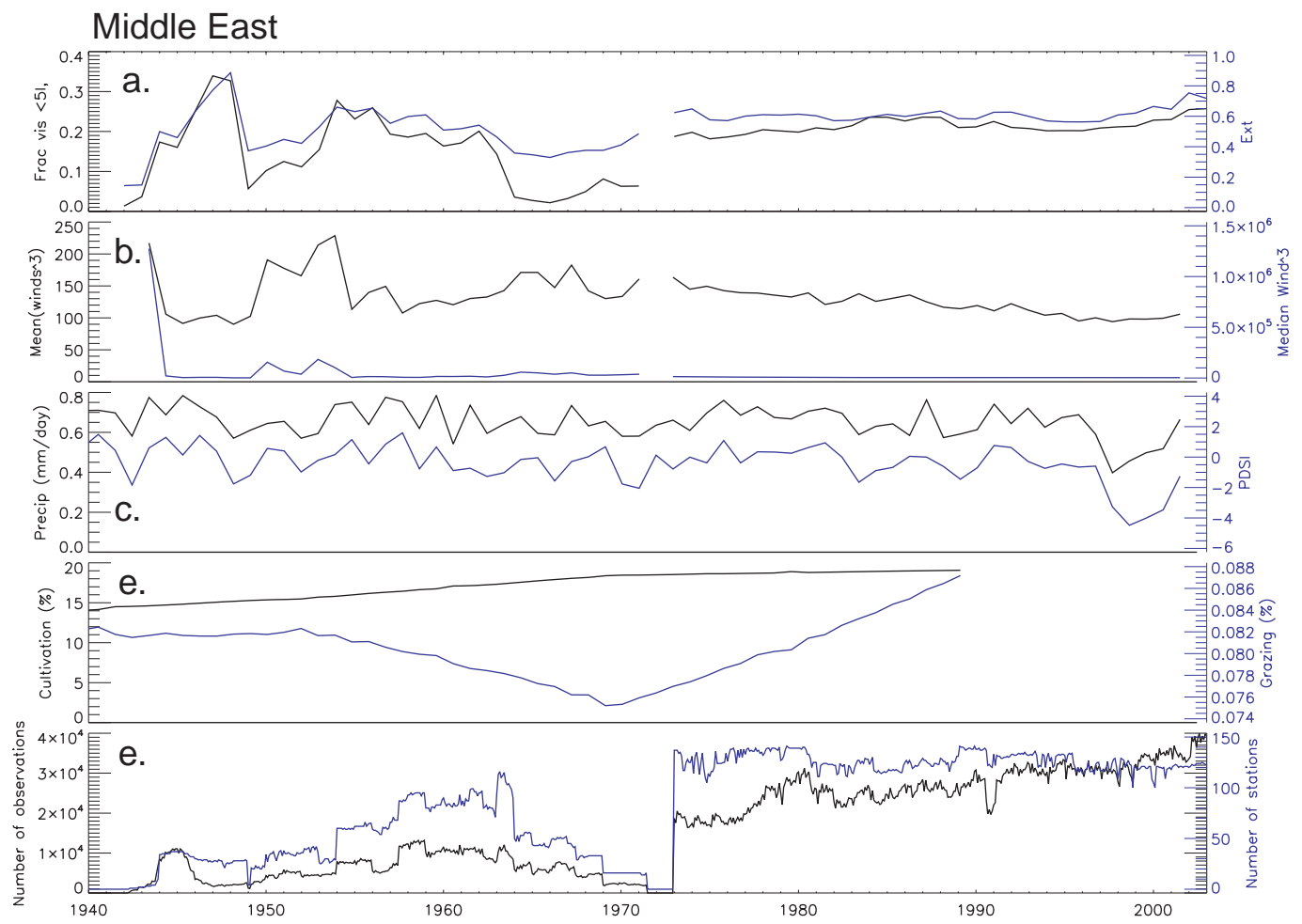

Fig. 10. Same as Fig. 6, but for the Middle East (region shown in Fig. 11). 

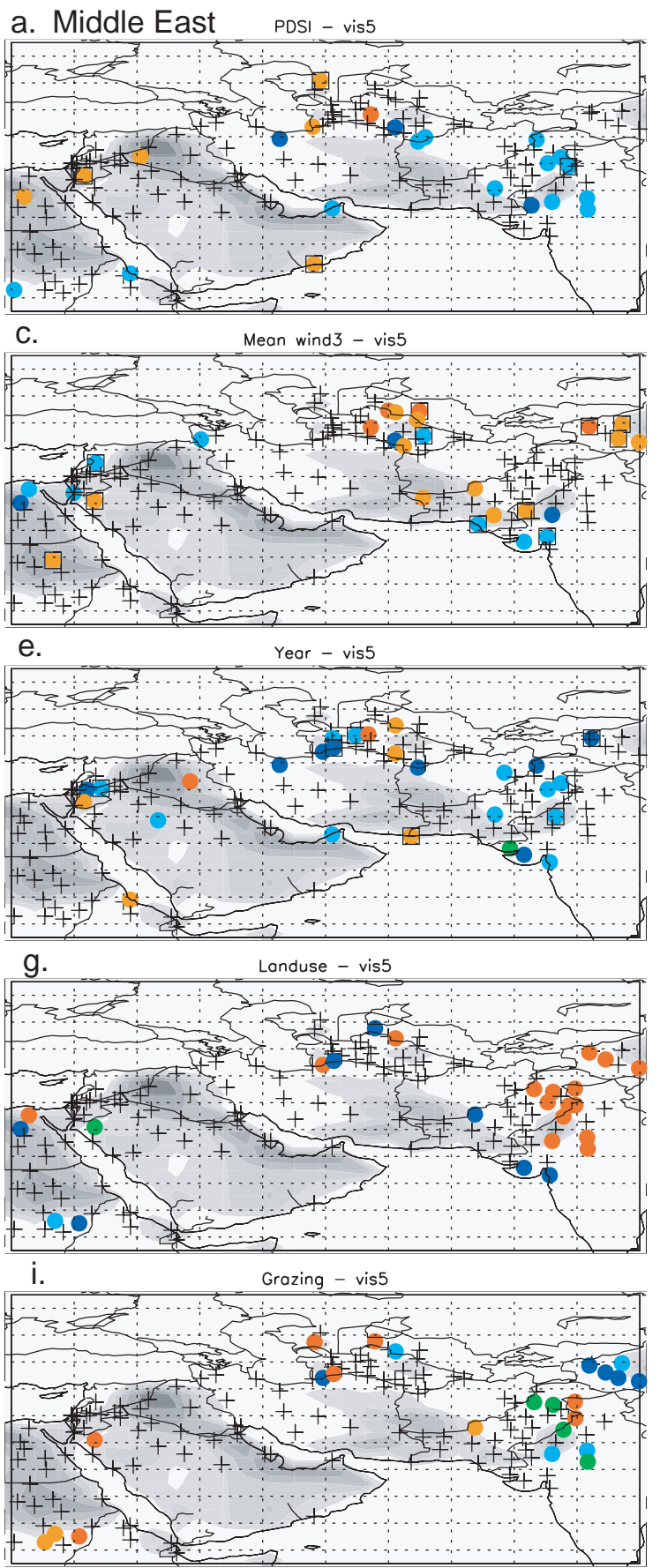

$-0.8$

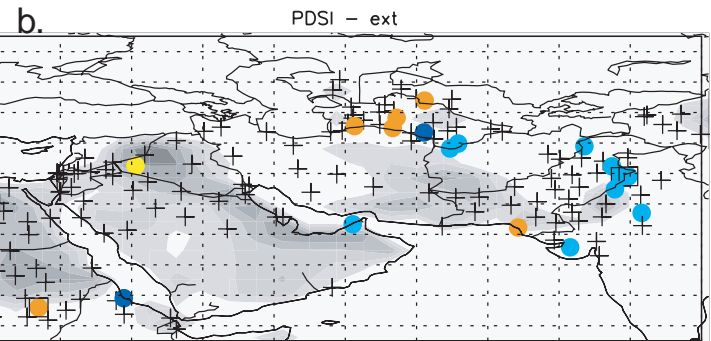

d.
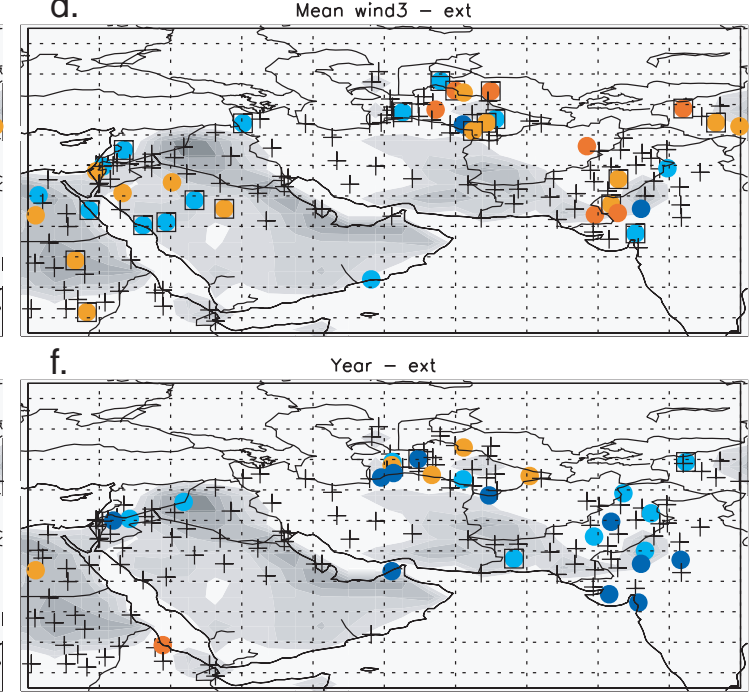

h.
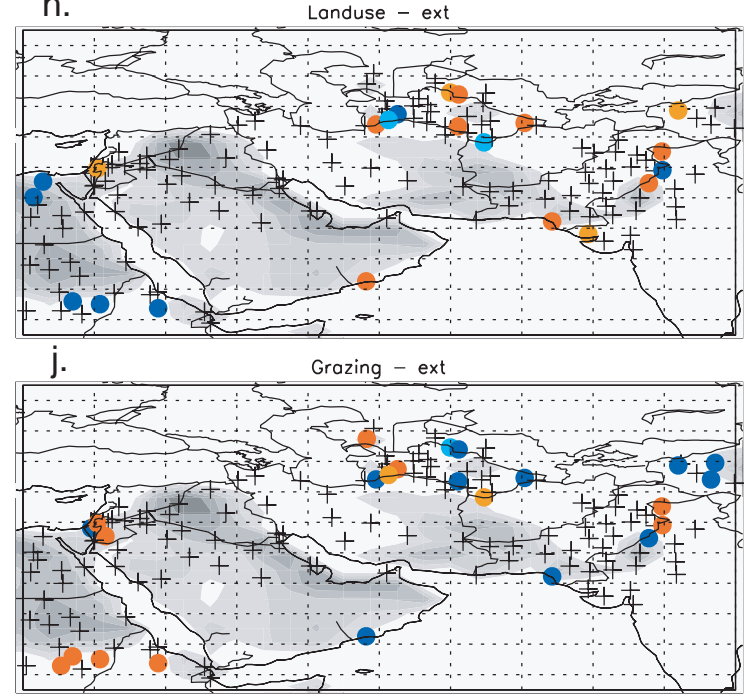

0.8

Fig. 11. Same as Fig. 6, but for the Middle East (ENSO and NAO are not included).

as in North Africa, but that there are statistically significant temporal trends. There are also correlations between human activities (cropland or grazing) and dust in different parts of the Middle East. There are statistically significant decreases in Pakistan/India over 1974-2003. If we look at correlations in Pakistsan/India over the longer time period (back to the 1940s) there are more stations with positive trends in VIS5 and EXT (not shown) and more statistically significant correlations with cropland and grazing (both positive and negative).

For the sources in and around China (see Fig. 1 or Fig. 5c for region), we tend to see high VIS5 and EXT in the 1950s, 


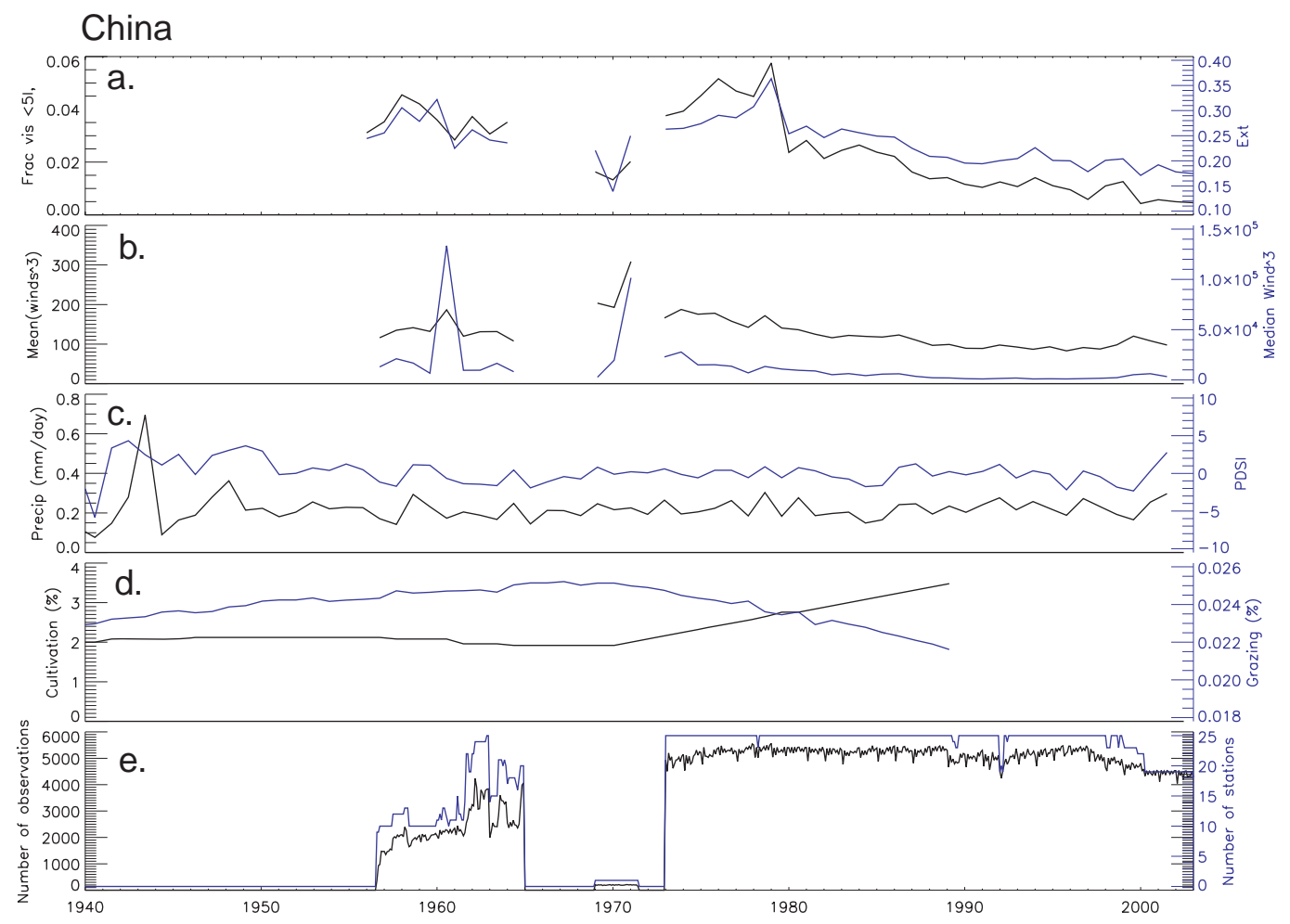

Fig. 12. Same as Fig. 6, but for a region near China (region shown in Fig. 13).

similar to other regions, and a downward trend between 1974 and 2003 (Fig. 12). Correlations between VIS5 and EXT and other variables (Fig. 13) suggest that precipitation is not important for variability in visibility, but that winds are correlated with variability in visibility, similar to the results seen in other studies (e.g. Zhang et al., 2003; Sun et al., 2001; Zhao et al., 2004; Liu et al., 2004). Our data do not show the increase in dustiness in 2000-2002 seen in Kurosaki and Mikami (2003), although our results are consistent with their conclusion that wind drives variability in dust events. Kurosaki and Mikami (2003) include in their analysis many stations close to urban areas in China, which are excluded in our analysis.

For Australia, there are fewer stations compared to the other regions previously discussed, but again we see the low visibility in the 1950s (with large standard deviations, not shown), with less variability between 1974 and 2003 in the VIS5 and EXT data. There is an exception in the year 1986, which is anomalously high, especially for VIS5 (Fig. 14). Correlations at specific stations (Fig. 15) suggest that PDSI has the strongest correlations with dust, but in a manner that is counterintuitive - the higher the water availability is, the more dust. This makes some sense as a dust correlation if the increasing water makes the soil more erodible because the water brings more erodible sediment into the dry fluvial channels and lake beds or breaks up crusts (e.g. Okin and Reheis, 2002; Mahowald et al., 2003a; Zender and Kwon,
2005. But this counterintuitive correlation could also be due to other aerosols or increasing water vapor changing visibility as well. There are downward trends in VIS5 and EXT over the 1974-2003 time periods at some stations (similar results are seen for Fig. 15 when the whole time period is considered). There are 2 (out of 16) stations with statistically significant correlations between VIS5 and ENSO, but these significant correlations are not matched between EXT and ENSO. (* This is in contrast to the correlation between El Nino and precipitation in many regions of Australia, although not necessarily across the dust region (Dai et al., 1998).

In South America, there are 7 stations with data for part of the time period. Again there are low visibilities at the first part of the time series, and then flatter visibility trends for the rest of the time series (Fig. 16). There are few correlations between the station data and other variables (Fig. 17). Some stations indicate that wind speeds are anti-correlated with VIS5 and EXT (which may indicate that these stations are not dust dominated and should be ignored), and there are some correlations between year, cropland, grazing and precipitation, but no large scale patterns. Only one station has a correlation between ENSO and EXT.

There are a couple of regions where our model does not predict the surface extinction to be dominated by dust, but where dust emissions may be important. We consider them briefly here, including all stations with more than 30 years 

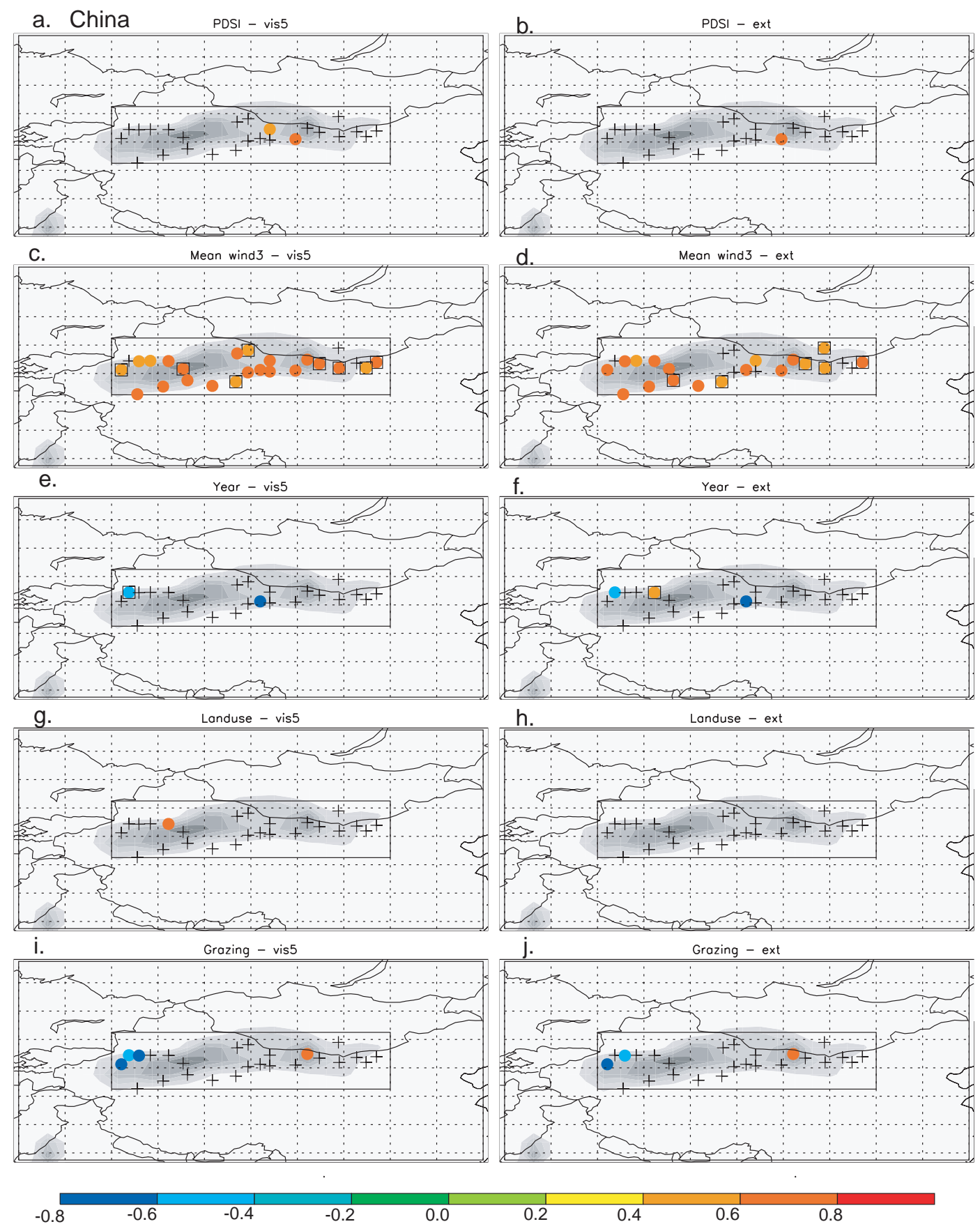

$-0.2$

0.0

0.2

0.6

0.8

Fig. 13. Same as Fig. 11, but for a region near China.

of data. First we look at the Southwestern U.S. region (e.g. Prospero et al., 2001) (Fig. 19 shows the region). A time series plot shows that both VIS5 and EXT have been roughly increasing since the 1940s, with a lot of variability (Fig. 18). For this region, the data are more regularly available prior to 1974 than in previous regions, so we show correlations from 1940 to 2003 (Fig. 19). There are statistically significant correlations between most of the variables and VIS5 or EXT.
Winds and antecedent PDSI are sometimes anti-correlated with VIS5, which is not intuitive. Increases in precipitation may bring in more easily erodible soil (Mahowald et al., 2003a; Okin and Reheis, 2002), but lower winds seem unlikely to contribute to greater dust sources, unless dust devils are important (e.g. de Renno et al., 1998). Both the results of the correlations, as well as the fact that these regions are not generally dominated by dust make the interpretation of 


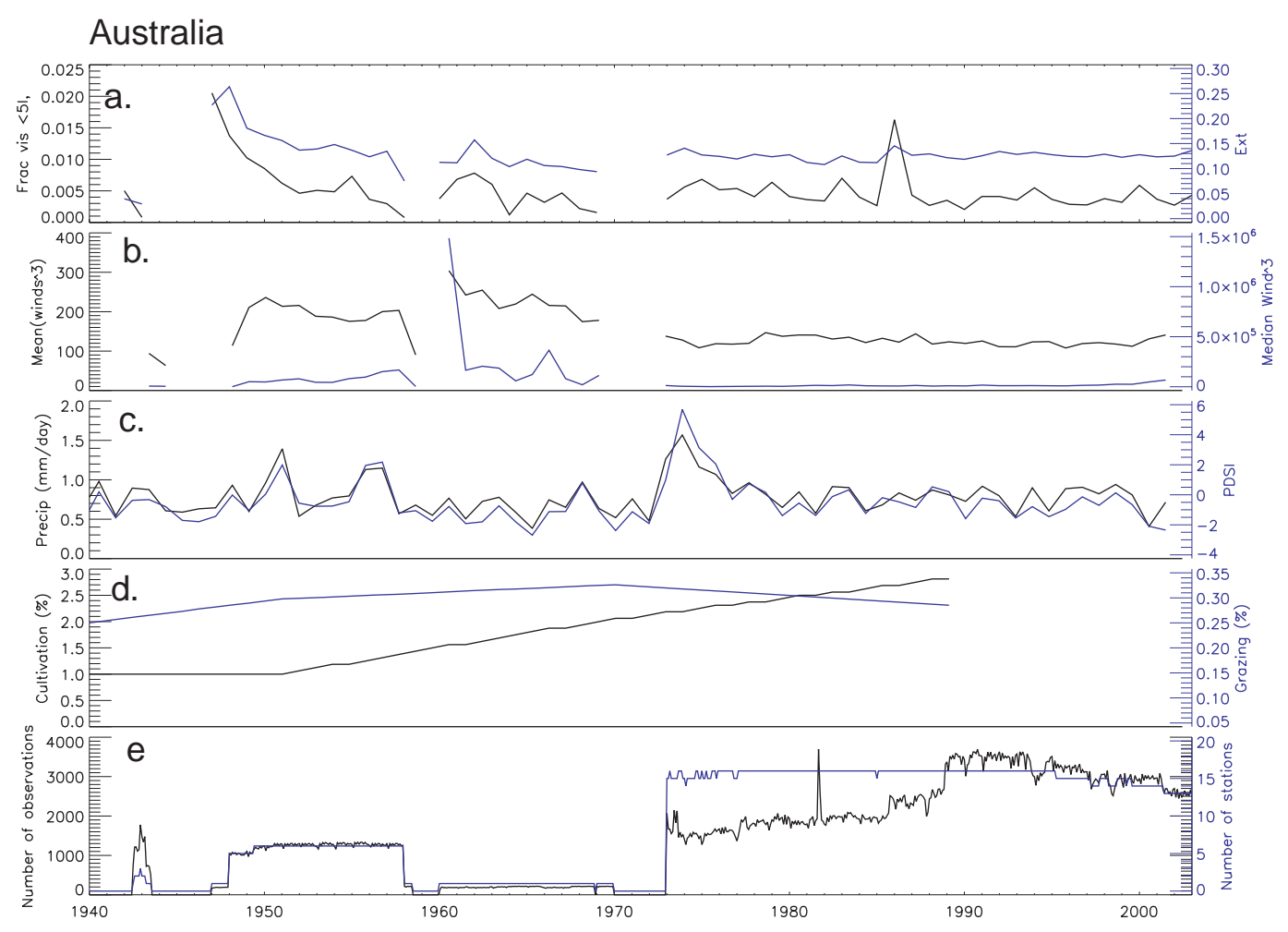

Fig. 14. Same as Fig. 6, but for a region in Australia (region shown in Fig. 15).

Table 3. Correlation coefficients with time and visibility-derived variables. If a significant correlation exists, this implies a trend with time. Only values significant at the $95 \%$ are shown here.

\begin{tabular}{lll}
\hline Region & EXT correlation with time & $\begin{array}{l}\text { VIS5 correlation with time } \\
1974-2003 \text { (whole time) }\end{array}$ \\
\hline All dusty regions & NS (NS) & NS (NS) \\
N. Africa & NS $(0.79)$ & NS $(0.43)$ \\
Middle East & $0.40(0.42)$ & $0.57(0.35)$ \\
China & $-0.86(-0.59)$ & $-0.89(-0.72)$ \\
Australia & NS (NS) & NS $(-0.30)$ \\
South America & NS $(-0.22)$ & $0.39(-0.40)$ \\
& & \\
\hline
\end{tabular}

these results difficult, and are consistent with the results of the model suggesting that visibility in this region is not dominated by dust.

The Aral Sea area is another region which is thought to have a great deal of dust (e.g. Prospero et al., 2001), although our model does not predict dust as the dominant source of surface extinction. VIS5 and EXT tended to be high during the 1950s, and are lower now (Fig. 20). Similarly, winds were higher in the 1950s than today. These might be indications that the data quality or location of the measurement devices have changed, or it could be an indication that there are real changes in the conditions in the Aral Sea. Similar to North America, the amount of data is relatively stable over the whole period of data (1940-2003), so we show correlations over the whole period (Fig. 21). There are strong correlations between wind speed cubed and VIS5 and EXT as well as between grazing and VIS5 or EXT. There are anticorrelations between VIS5 and EXT and cropland and year. Studies have shown that Aral Sea levels have dropped dramatically, and that the area of the Sea has been reduced by about $80 \%$ in recent decades. There have only been anecdotal studies of the changes in dustiness of the region (e.g. Smith et al., 1999). The visibility-based data do not support a decrease in visibility since the 1940s. This could be because of shifts in winds as the lake has dried up. 

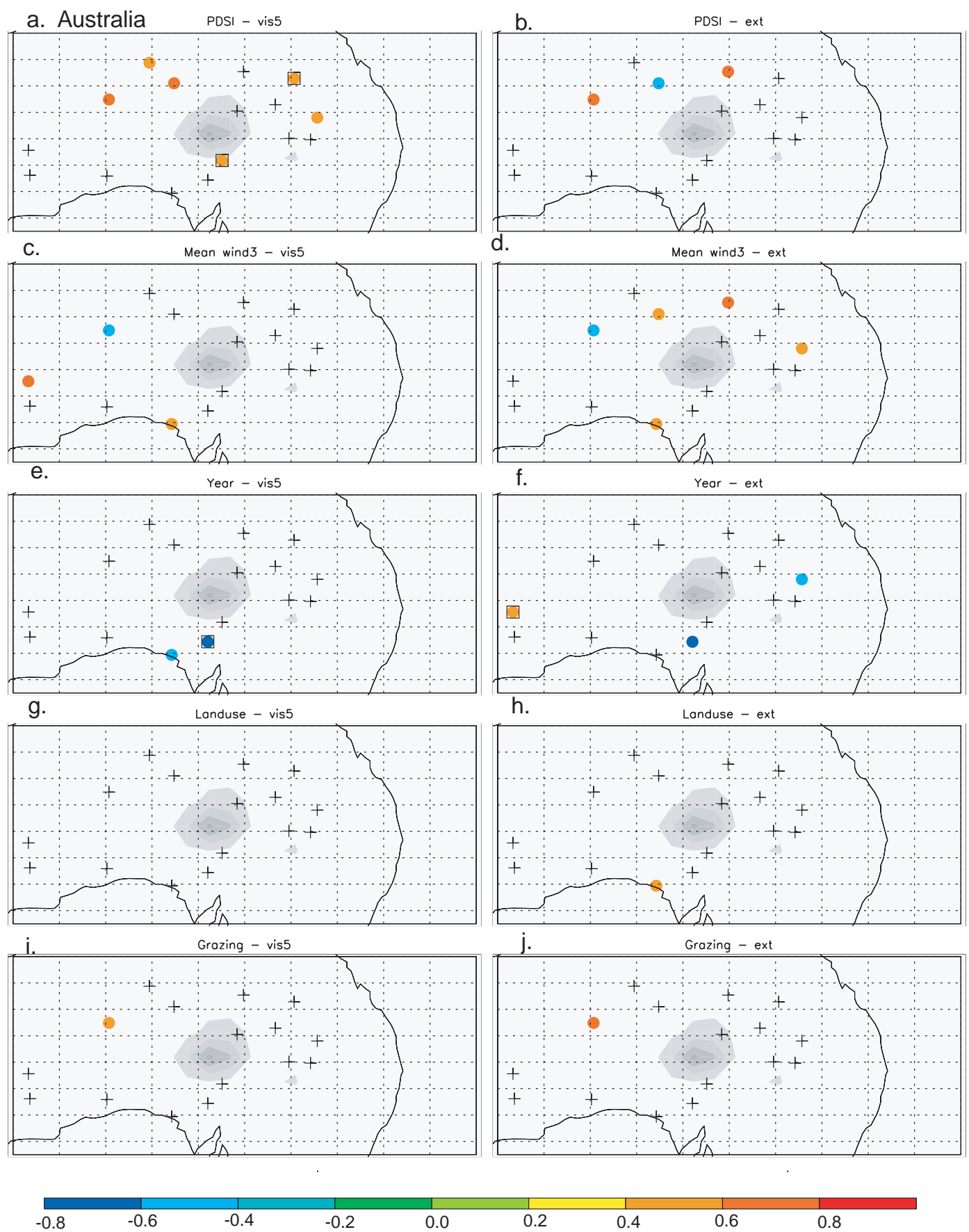

0.0

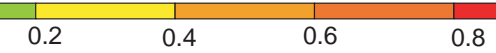

Fig. 15. Same as Fig. 11, but for a region near Australia.

If we consider the average of all 357 stations in dusty regions (Fig. 22), we see that the 1940s and 1950s were periods with relatively high VIS5 and EXT. These were more windy periods, although there is also more variability in winds. It is interesting that there was higher VIS5 and EXT during this period, but it raises a question about the data. It could be that during this period, there were more dirt roads close to the meteorological stations, and this caused lower visibil- ity. This was a period of rapid changes due to the World War and technological development. There may also have been an increase in soil conservation efforts in cultivated areas after this time period. But these results could also be an indication that the measurement techniques are not consistent across our entire time period. Overall, the appearance of a peak in both EXT and VIS5 at the beginning of our time series, when the data were relatively sparse, appears 


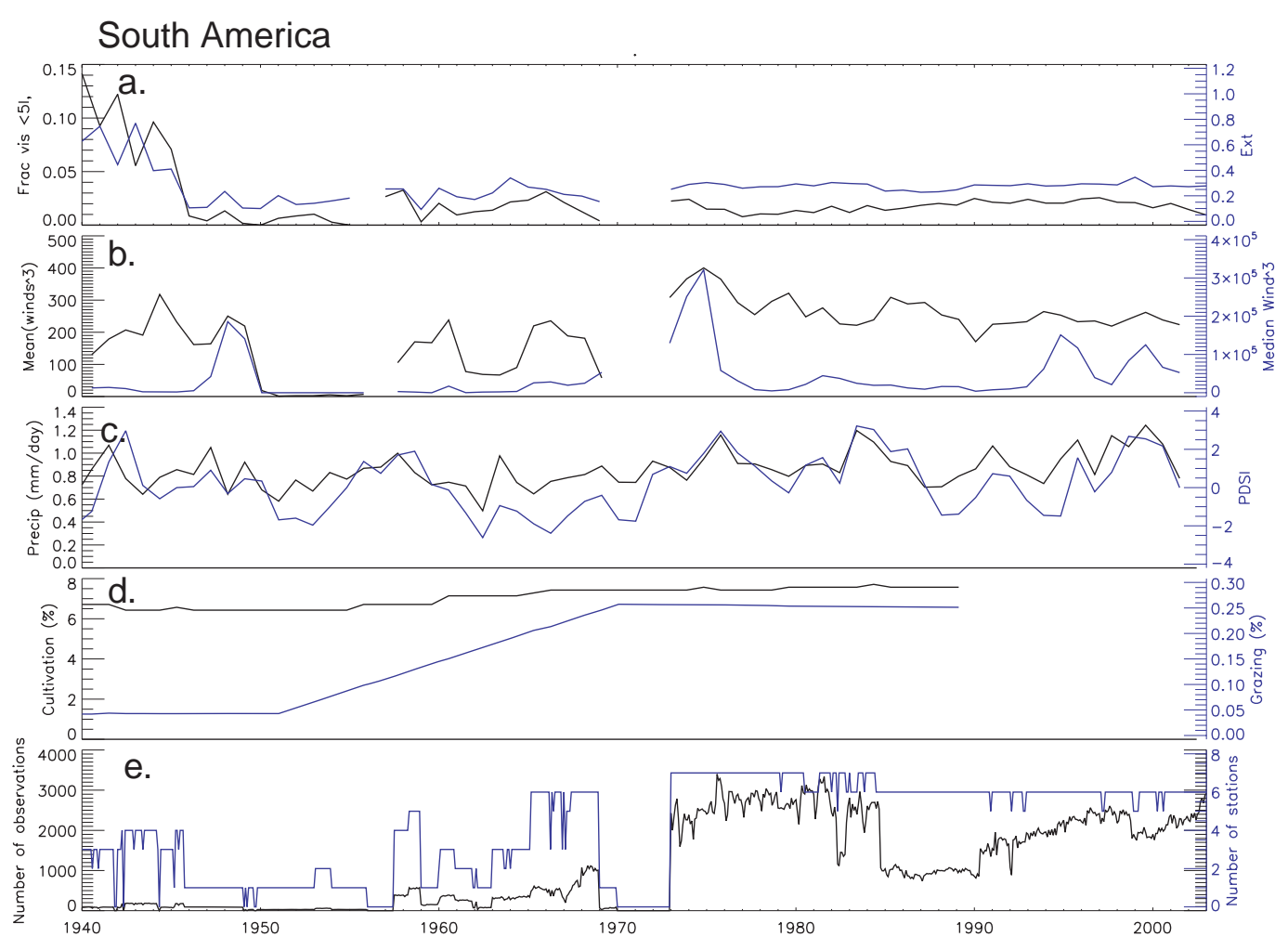

Fig. 16. Same as for Fig. 6, but for a region in South America (shown in Fig. 17).

suspicious. Thus, we may want to readdress previous studies which have suggested the 1950s were dustier in China than current (Zijiang and Guocai, 2003), as an example, and see if there are independent datasets which allow us to check that this result is not because of biases in the data collection method. On the other hand, it is possible that the 1940s and 1950s were a much dustier time period in all dust regions globally. Over the whole time period, there is no statistically significant trend in EXT or VIS5 for all regions taken together. For some regions (China, Middle East or South America) there are statistically significant trends with time in the visibility-derived variables over the whole time period or 1974-2003 (see Table 3).

Another way to analyze the same data is to look at correlations between VIS5 and EXT and other variables not over time, but in space across the stations. If we look at the spatial correlations across all regions using the means over all years (or over 1974-2003, the results do not change qualitatively), we can look at some different hypotheses about drivers of dust variability spatially. For the correlations between visibility parameters and topographic lows we use three representations: the preferential source distribution of Ginoux et al. (2001), the dust source used in the NCAR Community Atmospheric Model (Mahowald et al., 2006) (which is based on the Zender et al. (2003b) geomorphic soil erodibility factor which calculates upstream area and satellite derived veg- etation, Bonan et al., 2002), or the surface reflectance-based sources of Grini and Zender (2004). In addition to the mean cropland extent from Ramankutty and Foley (1998) used in the main part of the study, we use a new cropland dataset being developed for 2000 (Ramankutty, personal communication). Table 4 shows the results of this analysis over the 357 stations in dust dominated regions. Only correlations that are significant at the $99 \%$ are shown, and we crudely include the impact of non-independence of the stations by reducing the number of degrees of freedom by 4 in the statistical significance calculation. Using VIS5 or EXT these results suggest that cultivation is the best determinant of spatial variability in dustiness, not wind speed or whether there are topographic lows nearby. The correlation coefficients between cropland extent (Ramankutty and Foley, 1998) and VIS5 and EXT are 0.55 and 0.45 respectively, consistent with cultivation being associated with $20-30 \%$ of the dustiness seen in the visibility record. We obtain similar results if we use the more recent dataset developed for the year 2000 (Ramankutty, in prep.), although this correlation is sensitive to the resolution of the cropland data. At too high of a resolution $(5 \mathrm{~min})$ the correlation decreases, probably because croplands which may be associated with dust sources are not located in the same $5 \mathrm{~min}$ grid box as our stations, but are located within the $100 \mathrm{~km}$ grid size. In addition, we can analyze several variables at the same time and see if more variability is captured. 
a. S. America
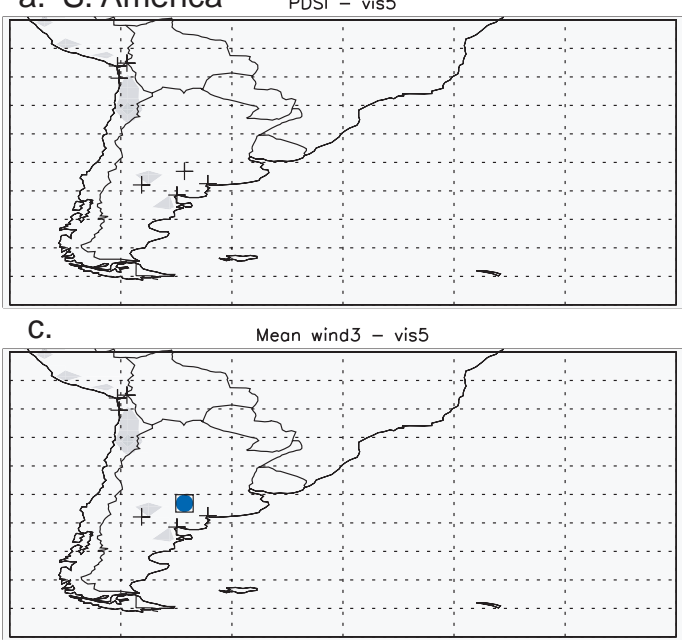

e.
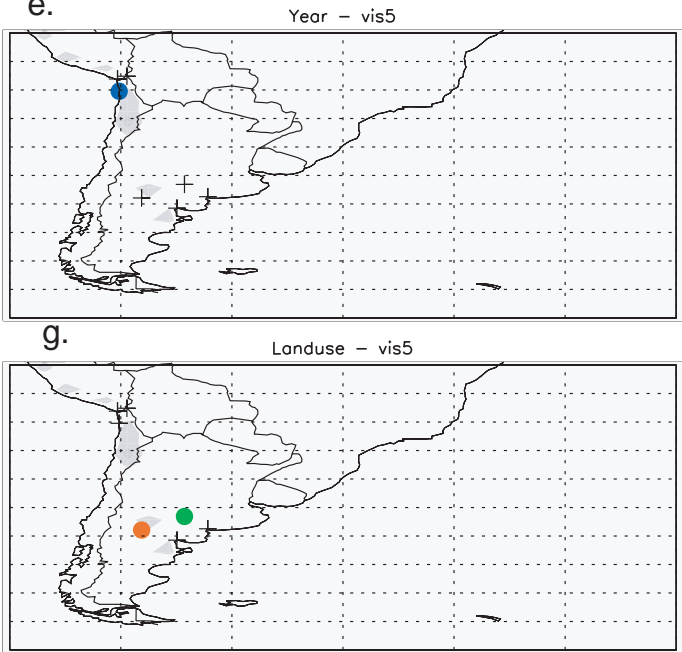

i.

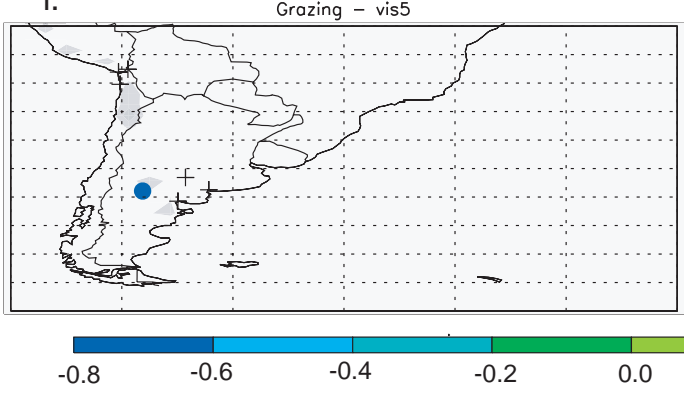

b.

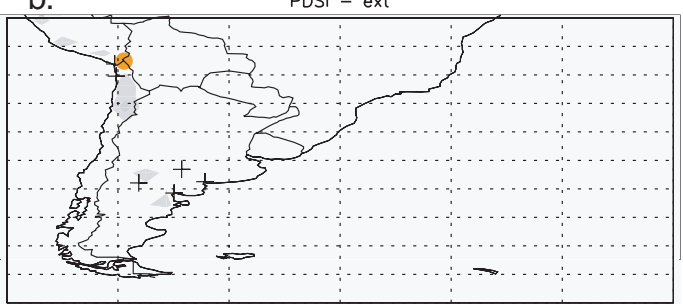

d.

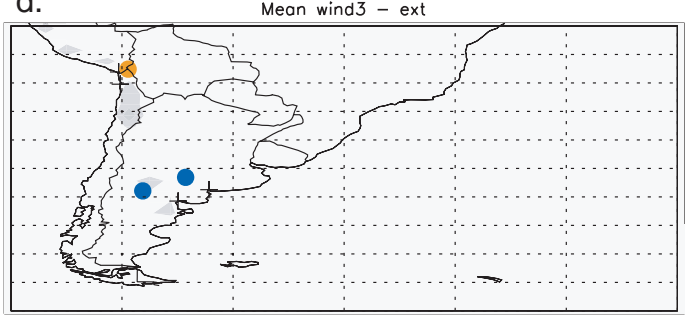

f.

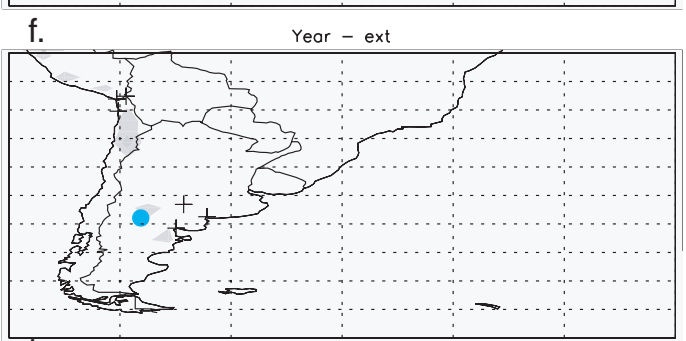

h.

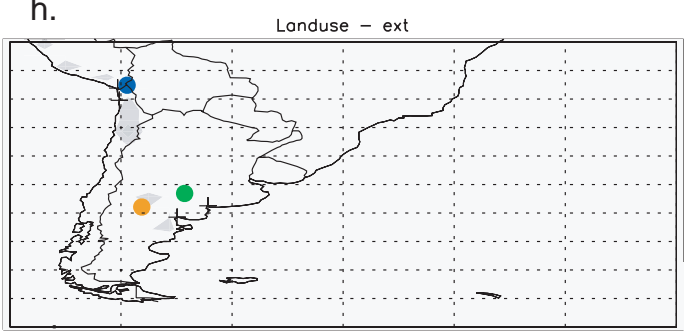

j.

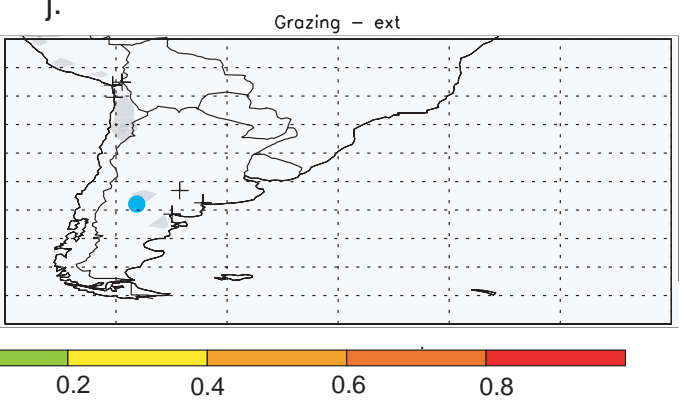

Fig. 17. Same as for Fig. 11, but for a region near South America.

If we include winds cubed, PDSI, croplands, grazing and topographic lows, slightly higher correlations coefficients are found than for any individual process ( 0.58 and 0.50 vs. 0.55 and 0.45 for VIS5 and EXT, respectively), and these results also suggest that cultivation is the most reliable variable for predicting visibility distributions. This result is consistent with the view of visibility that we obtain from Fig. 5, where the lowest visibility (i.e. highest VIS5 and EXT) is observed in Pakistan and northwestern India, where cultivation in an arid region may be contributing to high rates of desertification (Middleton and Thomas, 1997).These correlations are driven by Indian and Pakistani stations. The correlation between land use and visibility may be due to biases, of course. For example, humans must be in a region in order for there to be either land use or a meteorological station. 


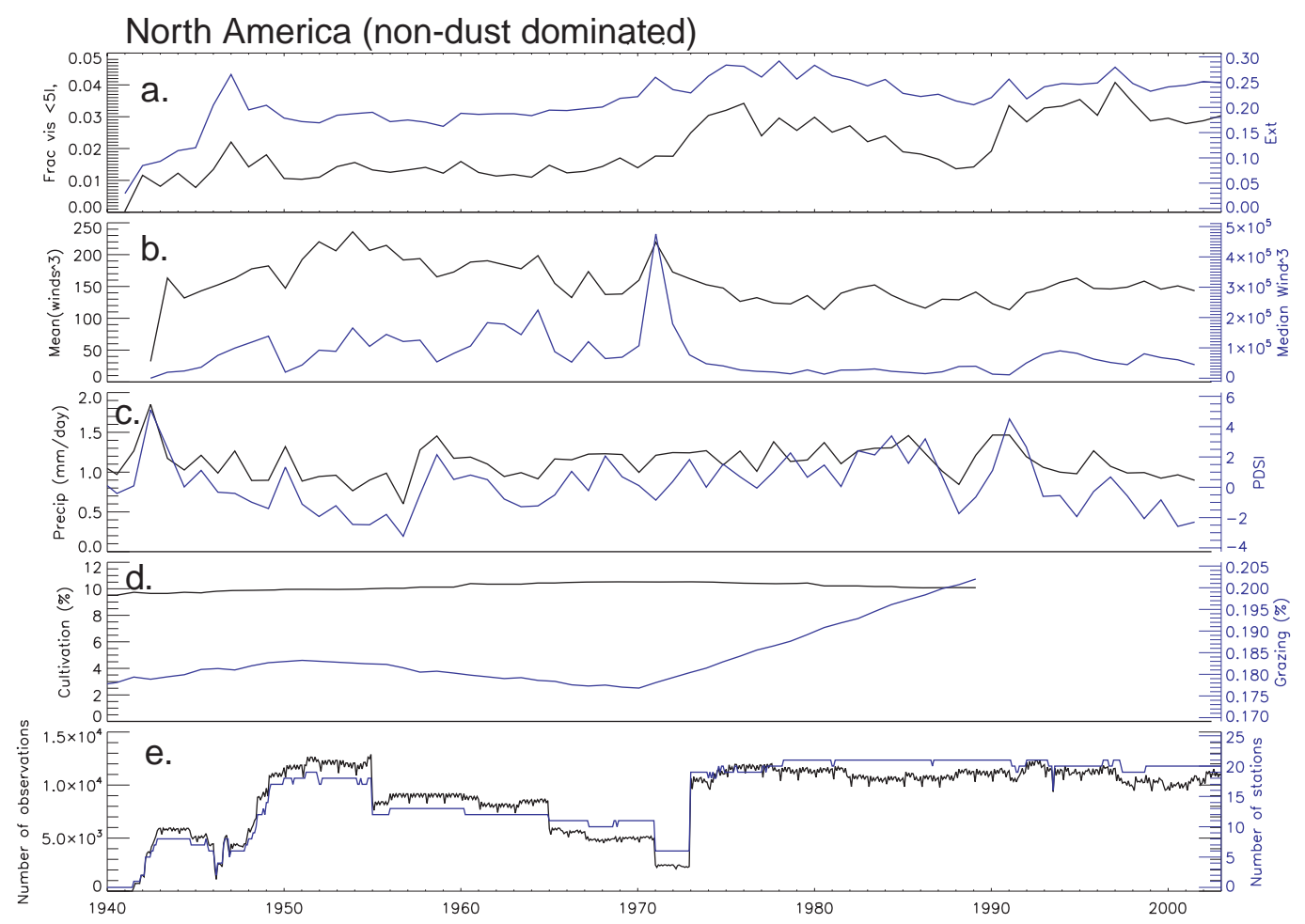

Fig. 18. Same as for Fig. 6, but for a region in North America (shown in Fig. 19 and Fig. 1). This region is one where the model predicts that dust does not dominate the aerosol extinction in the surface layer.

Table 4. Spatial correlations between visibility-derived variables and other variables (values not significant at the $99 \%$ are indicated by NS; NA indicates no data).

\begin{tabular}{lllll}
\hline Variable & VIS5 & EXT & VIS1 & Blowing dust \\
\hline Mean winds cubed & NS & NS & NS & NA \\
Median winds & -0.27 & -0.21 & NS & NA \\
$\begin{array}{l}\text { Precipitation } \\
\text { PDSI }\end{array}$ & NS & NS & NS & -0.39 \\
$\begin{array}{l}\text { Cultivation (Ramankutty } \\
\text { and Foley, 1998) }\end{array}$ & 0.55 & 0.45 & NS & NS \\
$\begin{array}{l}\text { Cultivation (Ramankutty, } \\
\text { personal communication) }\end{array}$ & 0.48 & 0.41 & NS & NS \\
$\begin{array}{l}\text { Grazing } \\
\text { Topographic low } \\
\text { (Ginoux et al., 2001) }\end{array}$ & NS & NS & NS & NS \\
$\begin{array}{l}\text { Topographic Low } \\
\text { (upstream area) }\end{array}$ & NS & NS & NS & 0.31 \\
$\begin{array}{l}\text { (Zender et al., 2003b) } \\
\text { Topographic low }\end{array}$ & & & & 0.41 \\
$\begin{array}{l}\text { (surface reflectance) } \\
\text { (Grini et al., 2004) }\end{array}$ & NS & NS & NS & 0.46 \\
\hline
\end{tabular}

These results are sensitive to which variable we use. If we use the fraction of visibility less than $1 \mathrm{~km}$ (also shown in Fig. 4 and Table 4), we obtain no statistically signifi- cant correlations with either topographic lows or human land use variables. However, if we use the dust storm frequency dataset described in Engelstaedter et al. (2003) (data courtesy 
a. N. America
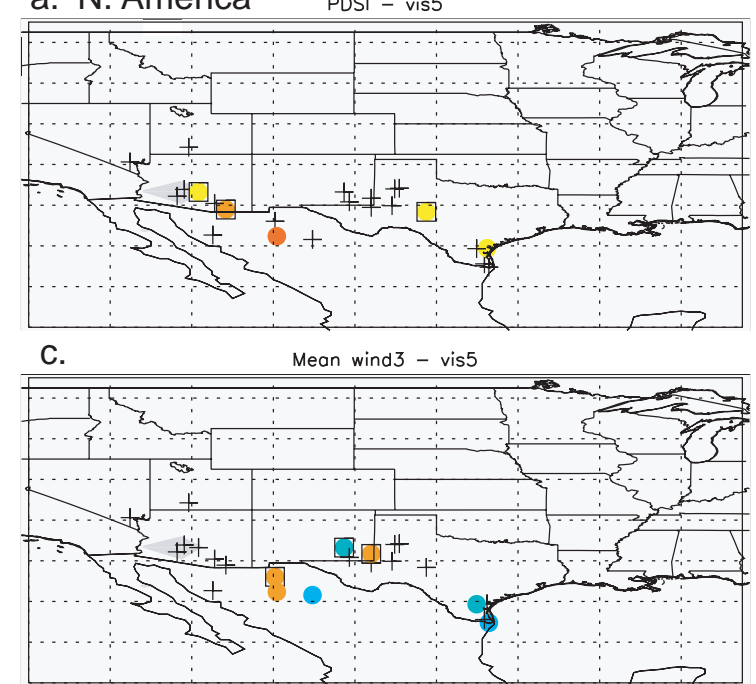

e.
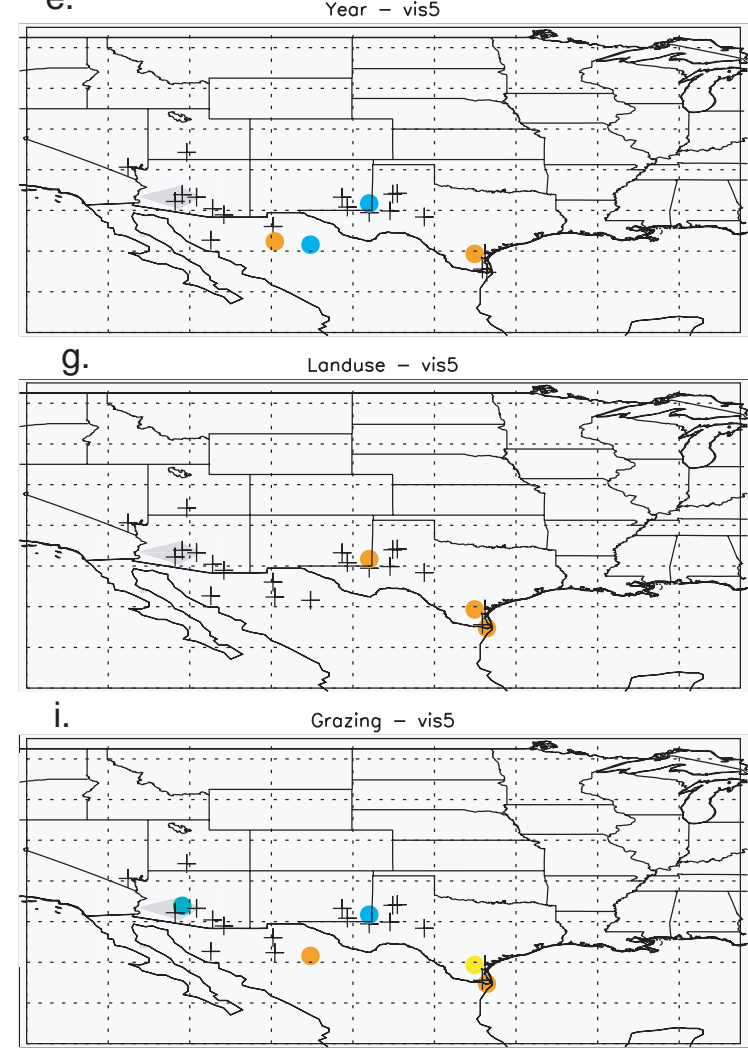

$-0.8$
$-0.6$
$-0.2$ b.
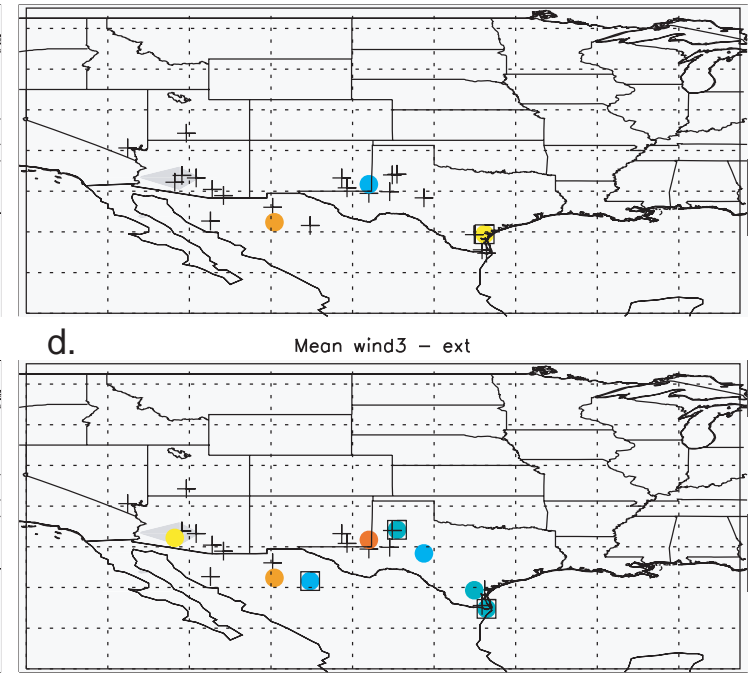

$\mathrm{f}$.

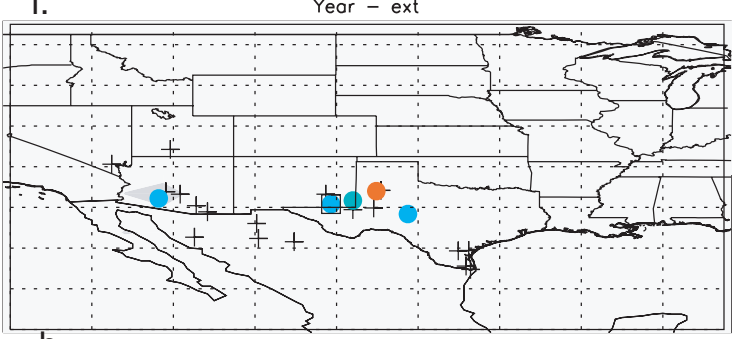

h.
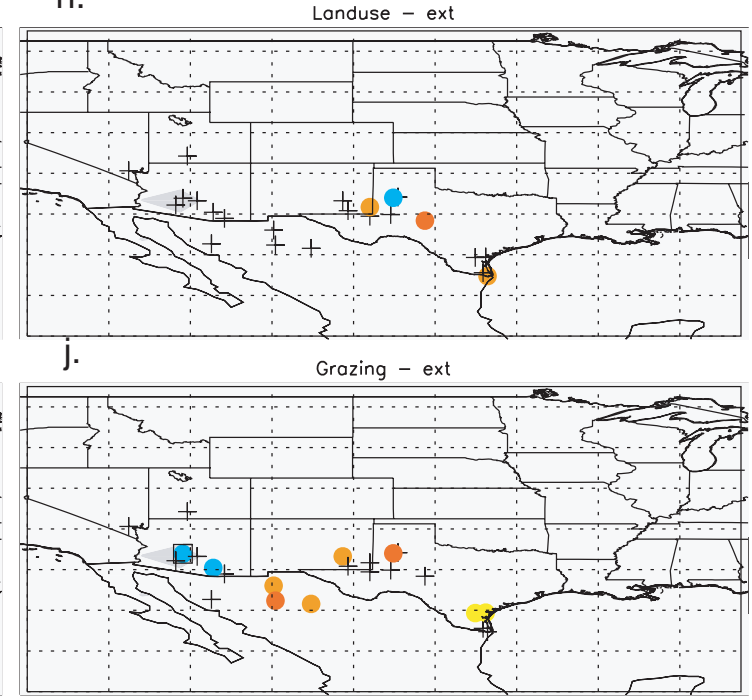

0.2
0.4

0.6

Fig. 19. Same as Fig. 11, but for a region in North America.

of I. Tegen and S. Engelstaedter), we obtain similar results to those obtained in that study (Fig. 4 and Table 4) - the dustiness in this dataset is correlated with natural dry lake beds, and not with land use proxies. In doing this comparison, we realized that the dust storm frequency dataset used in Engelstaedter, et al. (2003) represents the number of days with blowing dust or sand per year (and is not derived from the visibility data, but from the atmospheric phenomenon dataset), not the fraction of days with visibility less than $1 \mathrm{~km}$. The original description of the datasets was unclear. 


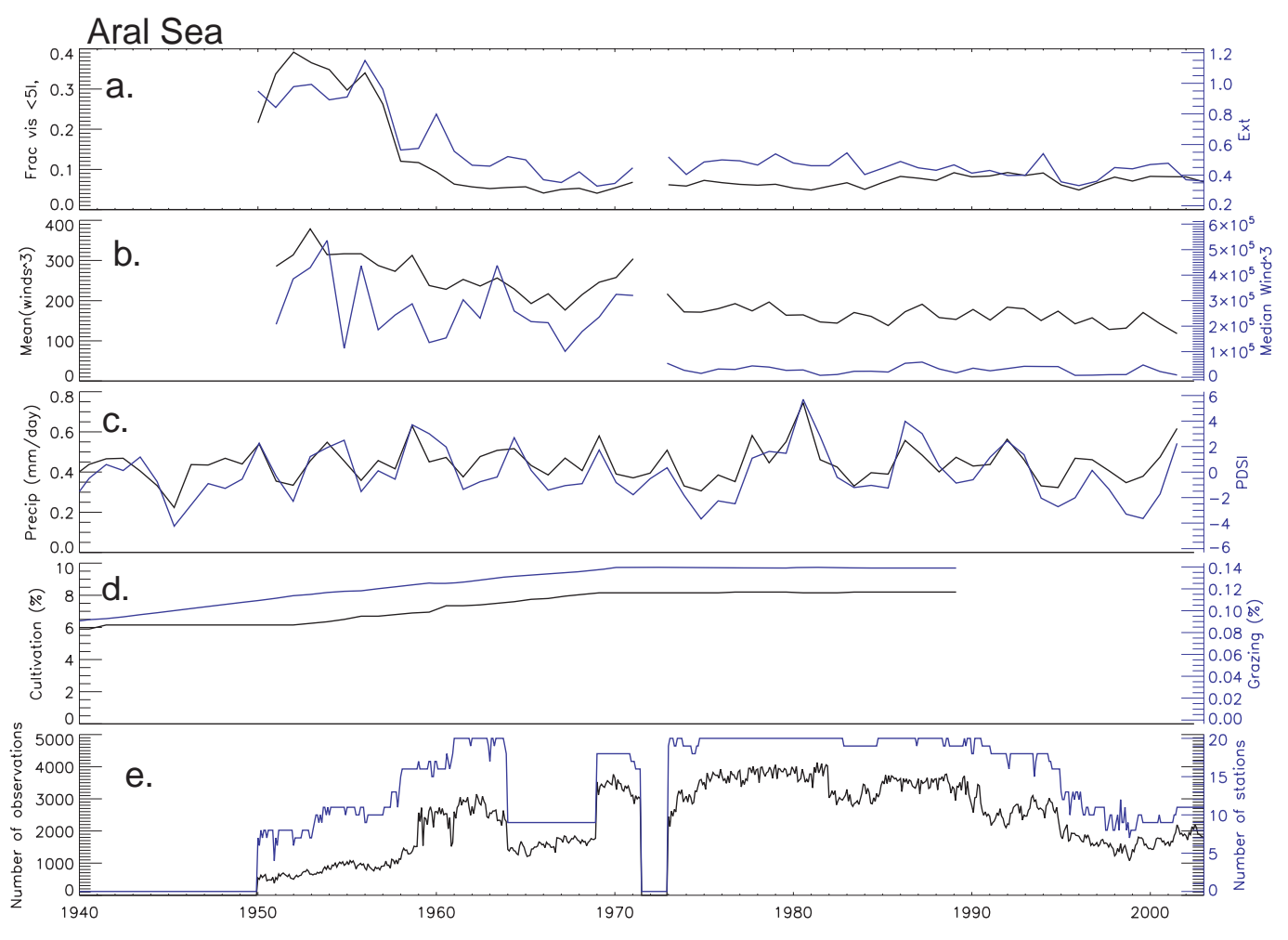

Fig. 20. Same as Fig. 6, but for a region near the Aral Sea (shown in Fig. 20 and Fig. 1). This region is one where the model predicts that dust does not dominate the aerosol extinction in the surface layer.

However, interpreting the dust storm frequency dataset used in Engelstaedter et al. (2003) as blowing dust or sand makes this dataset consistent with the results of this and other previous studies which analyzed data at particular stations (e.g. N'Tchayi Mbourou et al., 1997).

We do not know which of these variables best represent the true location of the dust sources, since we do not know where the sources are. Here, we emphasize the results based on the VIS5 and EXT visibility-derived variables, since we are able to correlate them with a known quantatity (AERONET aerosol optical depth in Sect. 3.1), and we think that the fraction of the VIS5 or EXT that correlates with the AERONET aerosol optical depth represents "regional" aerosols, not a very local source.

\section{Summary and conclusions}

This study focuses on using visibility data from surface meteorological stations as an indicator of dust variability, and specifically dust source variability. Because the quantitative nature of visibility data is not well established, we first evaluate the utility visibility data for our purposes. Our goal is to look at long term variability, so we use the monthly mean AERONET aerosol optical depth (AOD) at the 33 stations with more than 3 years of data. While AERONET data are high quality, it is not available as spatially or temporally extensively as the visibility data.

For each AERONET station, the monthly mean AOD values are compared to visibility-derived variables at the closest meteorological station. We do this to see what portion of the visibility is related to aerosols that are seen in high quality aerosol optical depth data and should represent more regional scale aerosols. At many stations there are no statistically significant correlations between the column aerosol optical depth and the visibility-derived variables, although theoretical calculations suggest there should be. Overall, for the surface extinction and monthly fraction of events with $<5 \mathrm{~km}$ visibility, the correlations are 0.25 and 0.33 , respectively, implying that between 4 and $9 \%$ of the variability in aerosol optical depth is captured by the visibility data. If we focus on stations that are predicted to be dominated by dust based on model calculations, we obtain overall correlations for extinction and fraction of observations with a visibility $<5 \mathrm{~km}$ of 0.47 and 0.46 , respectively. These results suggest that about $22 \%$ of the variability in the optical depths is captured in the visibility-derived variables. We tested several different visibility-derived variables, and results suggest that the fraction of observations with a visibility less than $1 \mathrm{~km}$ is less well correlated with aerosol optical depth than either fraction of visibility less than $5 \mathrm{~km}$ (VIS5) or averaged surface extinction (EXT; related to 1/visibility), so we used 
a. Aral Sea

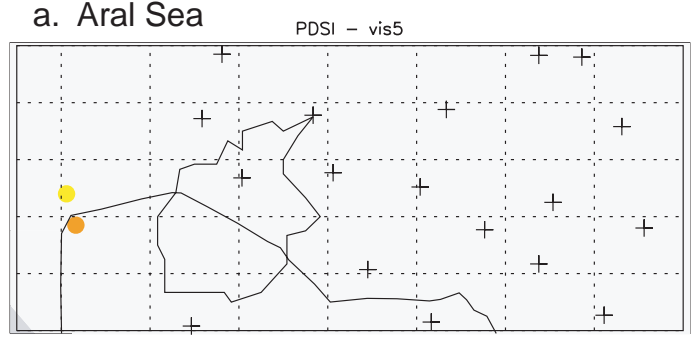

c.
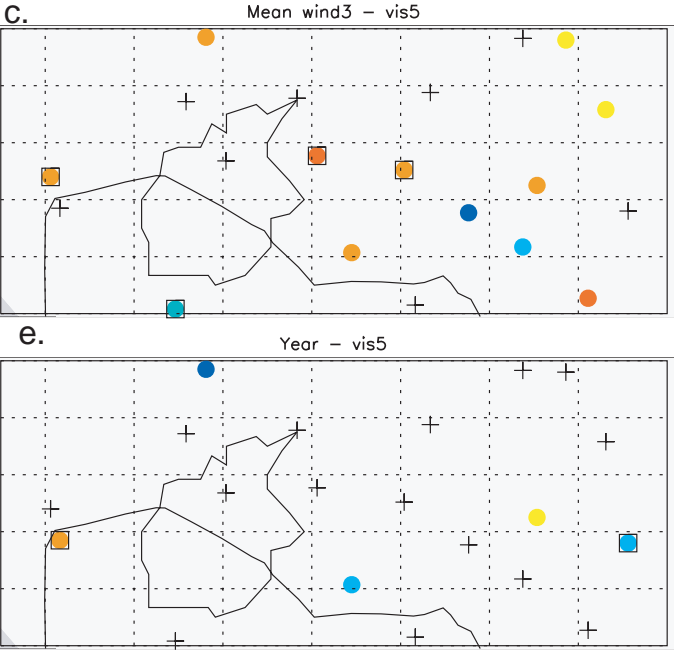

g.
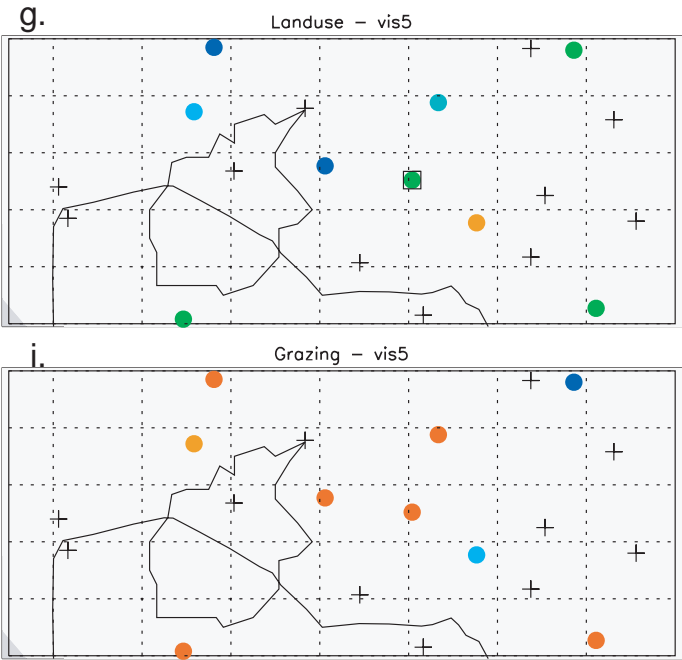

$-0.8$

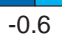

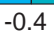

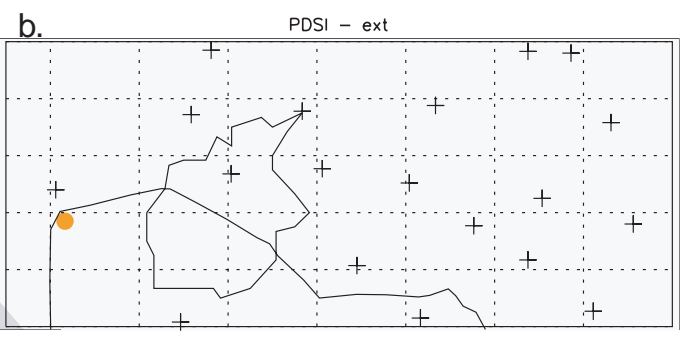

d.
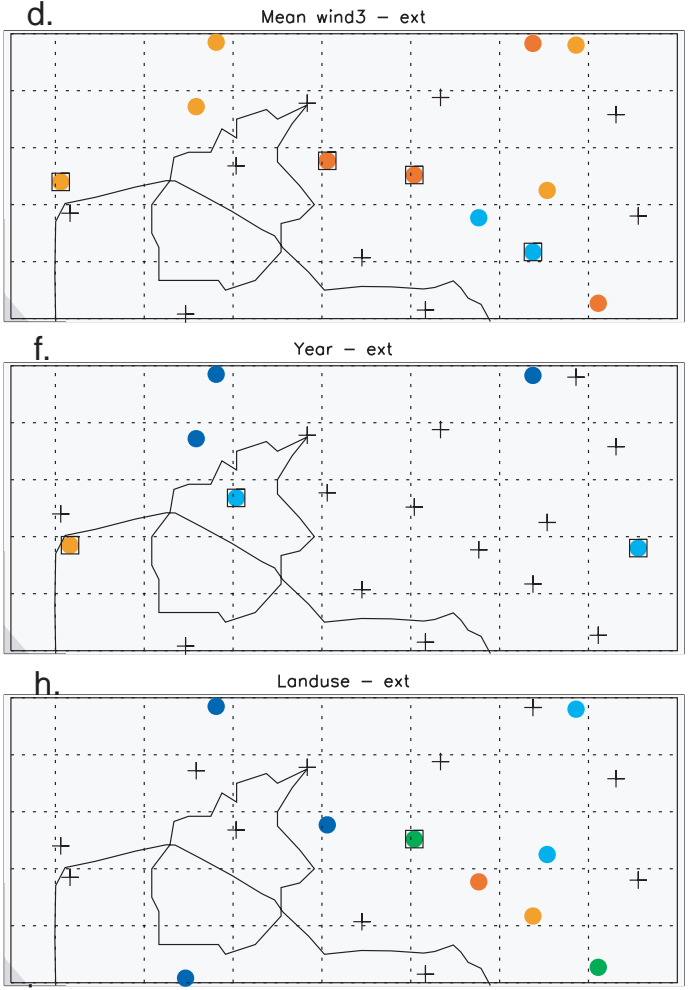

j.

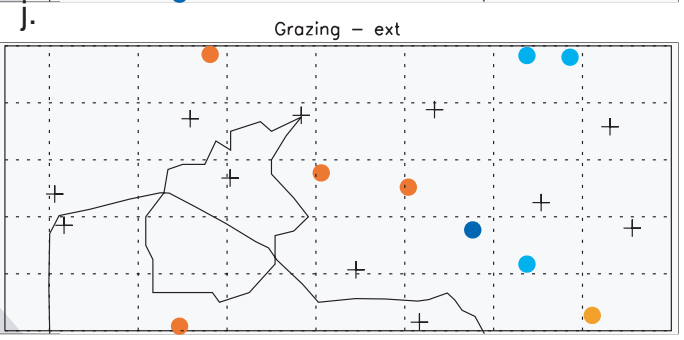

0.8

Fig. 21. Same as Fig. 11, but for a region near the Aral Sea.

those variables for most of the analyses in this paper. The fraction of observations with visibility less than $1 \mathrm{~km}$ may be indicative of some other important value, but we do not know how to evaluate its accuracy.

Similar correlation analyses using the TOMS AAI and TOMS AOD data suggest that they are able to capture about $45-49 \%$ of the variability in the AERONET optical depth data over dusty regions (correlation coefficients of 0.67 and
0.7). Note that the TOMS AOD only has a correlation coefficient of 0.23 over all AERONET stations, suggesting that it is not a robust measure of temporally and spatial variability in aerosol optical depth in non-dusty regions, even ignoring problems in satellite drift outside the 1984-1990 period.

For this study, and many previous studies, we use measures of dust AOD or surface extinction to infer the location and temporal variability of dust source surface fluxes, 


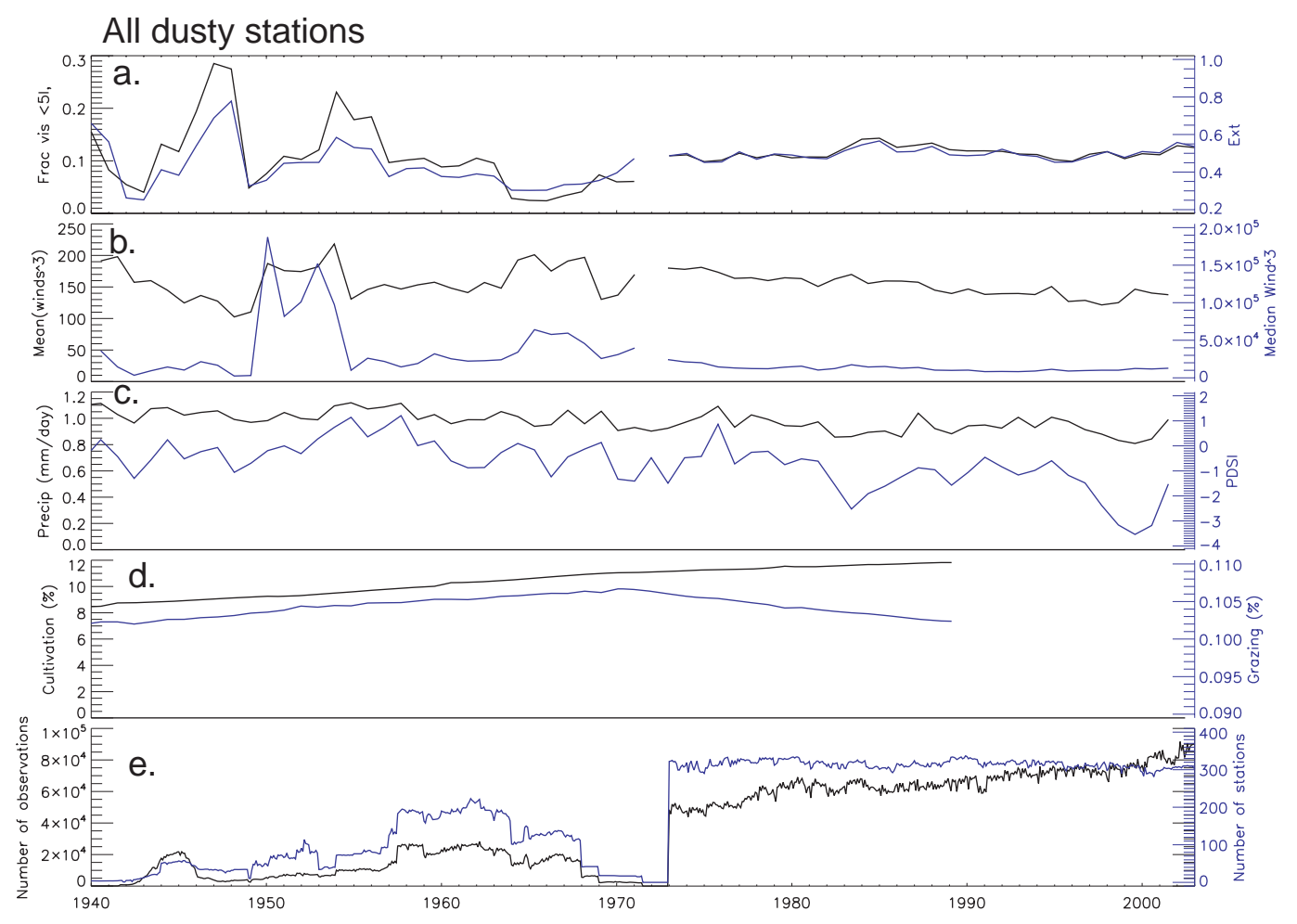

Fig. 22. Same as Fig. 6, but for an average across all the dusty stations considered in this study.

since we cannot directly measure dust source surface fluxes globally. Using models we can better understand which variables best represent the spatial and temporal variability in dust source surface fluxes. Our calculations show that surface extinction should be much better related to source surface fluxes of dust than column amount (correlation coefficient of 0.73 vs. 0.38 , equals $36 \%$ vs. $10 \%$ of variability, respectively). However, the visibility data has problems with its quality. Thus, it is unclear whether satellite aerosol optical depth or visibility-derived variability best gives information about variability in dust sources (either spatial or temporal). Some studies assume that TOMS AAI represents the long-range transported dust (e.g. Prospero et al., 2002). Because TOMS AAI is linearly proportional to the height of the dust, this is probably true (Torres et al., 1998; Mahowald and Dufresne, 2004). However, this also makes TOMS AAI less appropriate for studying spatial or temporal variability in dust source fluxes. The visibility-derived-proxies represent regional aerosols to the extent that they correlate with the AERONET AODs, and thus represent dust that has been transported somewhere from the kilometer to the hundreds of kilometers scale. The analysis here suggests that visibility data and TOMS AAI or TOMS AOD may be equivalently good (or bad) at representing the spatial and temporal variability in surface dust fluxes. Indeed, from their characteristics, TOMS AAI will get higher altitude dust while visibility data will see dust confined to close to the surface. More work on determining better ways to determine the location of dust source areas is vital, since the two main datasets we have to address dust sources (satellite optical depths or visibility data) show different results. We examined the temporal trends in VIS5 and EXT in regions dominated by dust, where the visibility-derived variables are able to capture over $20 \%$ of the variability in aerosol optical depth measured by AERONET. Although meteorological station data are available from 1900 to 2003, in dusty regions there are only data after 1940 in our dataset. The data record prior to 1974 is not consistent, forcing us to limit our analysis of "long" term trends to the last 30 years. This is disappointing, since we had hoped to extend the satellite record significantly into the pre-1980s period. This implies we are missing any processes occurring prior to the 1970 s.

Analysis of the temporal variability in VIS5 and EXT shows that there are maxima in the 1940s and 1950s throughout most of the dust regions. It is unclear whether these maxima occur because this was a dustier time period, or because of changes in measurement methods, scarceness of the data during this period, or an increase in dirt roads (which were later paved) or changes in farming practices (contour plowing, no-till agriculture and crop land intensification). In order to better understand what happened in the 1940s to 1950 s, we should try to find independent datasets before concluding that it was a dustier period. 
There are a relatively stable number of observations after 1974 in the dataset over dusty regions, so we conducted most of our correlation analyses between individual station time series of VIS5 or EXT and other variables during the period 1974-2003. For analysis we present simple and more commonly used correlation coefficients, but rank correlations show qualitatively similar results. However, in many cases, there are multiple variables which correlate with the visibility-derived proxies, making it more difficult to interpret the results. We focus on results that are regionally coherent. The high correlation coefficients between annually averaged PDSI and both VIS5 and EXT are consistent with precipitation being very important in the Sahel region of North Africa and the Mediterranean coast of North Africa. High correlations between winds and VIS5 or EXT in China are consistent with winds driving much of the variability of dustiness in China. In other regions, the correlation coefficients are not statistically significant on a regional basis. In no region are there large numbers of strong correlations between either NAO or ENSO and visibility, unlike what is seen farther downwind (e.g. Moulin et al., 1997; Mahowald et al., 2003b; Prospero and Lamb, 2003; Moulin and Chiapello, 2004). Temporally, correlations between human cultivation or grazing and visibility-derived variables are not seen over large regions in our datasets, perhaps due to the poor temporal quality of the cultivation and grazing datasets.

There are regions with statistically significant trends with time in VIS5 or EXT for the period 1974-2003 (seen as a correlation between year and these variables). Upward trends with time are seen regionally in parts of North Africa, especially in EXT, correlated with lower precipitation. Downward trends are seen in regionally broader areas, including parts of Central Asia and China. Looking at the average across all 357 stations in dusty regions, there is no statistically significant trend in VIS5 or EXT. Note that analyses of North America and the region close to Aral Sea (while more uncertain because these regions' visibility is not dominated by mineral aerosols) suggest that EXT and VIS5 are decreasing in these regions.

We get a different picture of the important processes if we look spatially across stations instead of at individual stations over time. The hypothesis that dry lake beds are dust sources is not supported, since there is no significant correlation between mean VIS5 or EXT in our data and three measures of the topographic lows (to the extent that topographic lows represent dry lakebeds). Instead the most consistent correlations are between VIS5 and EXT and cultivation across all regions, with correlation coefficients suggesting that approximately $30 \%$ of the spatial distribution in the dustiness in the stations is associated with cultivation (note this does not mean that the cultivation source of dust is $30 \%$ of the dust flux, because of the statistics used here). Most of this cultivation related dustiness appears to be in the Pakistan/India region (see Fig. 5). This may indicate that the results here may be sensitive to the quality of this data as a reflection of dust sources. We may be seeing a different signal in the spatial versus temporal analysis because most of the dust sources may have been generated prior to 1974 in the cultivated regions. To add complexity to this isue, if we use a different meteorological dataset based on blowing dust or sand (as used in Engelstaedter et al., 2003), dry lake beds or topographic lows are consistent with the data (correlation coefficients between 0.3 and 0.46 ), but cultivation is not.

The hypothesis that most dust comes from topographic lows is supported from the TOMS AAI data, geomorphic data and the blowing sand and dust data (e.g. Goudie and Middleton, 2001; Prospero et al., 2002; Engelstaedter et al., 2003). However, the visibility data do not support that hypothesis. Which dataset should we believe? According to the analysis here, it is likely that the visibility-derived data used here or TOMS AAI or TOMS AOD are equally good (or bad) at inferring the spatial and temporal variability of dust surface fluxes. In addition, the TOMS AAI retrieval method is biased to show higher values in dry topographic lows in desert regions than in other nearby regions (Mahowald and Dufresne, 2004). Thus, this paper suggests we may need to re-examine the hypothesis that topographic lows are the dominant source of dust. Using datasets that represent the vegetation, land use, and underlying soils and landforms would provide a more physical basis from which to understand dust sources (e.g. Ballantine et al., 2005) Because of the known biases of the TOMS AAI specifically, and the poor correlation of AOD with dust surface fluxes, other datasets should be used to improve our understanding of dust sources.

Any conclusions about what drives variability in desert dust sources based on visibility data must include a caveat, because of the question about the quality of the data. Comparisons suggest that the visibility data only capture about $22 \%$ of the variability in aerosol optical depth, and thus may be describing only about $20 \%$ of our dust source variability (assuming that our data are Gaussian, which they are not). However, visibility datasets are more extensive in time and space than our other datasets, and may be as good as datasets from satellites at looking at surface emissions of dust (e.g. TOMS AAI or TOMS AOD). The visibility data sets here suggest very little global trend in dustiness for the period of 1974-2003. One of the major problems with predicting changes in desert dust sources and loading is de-convolving the relative roles of climate change, carbon dioxide fertilization and land use in impacting dust mobilization. The temporal analysis performed in this study suggests that climate variability and change (through wind changes, and the impact of changes in soil moisture from precipitation and surface temperature changes) and potentially carbon dioxide fertilization, and not human land use practices, drive temporal changes in dust sources between 1974 and 2003 in some regions. However, spatial analysis of dustiness seen in the visibility record is consistent with a large fraction of the dustiness being associated with human land use, primarily in Pakistan and India. Therefore this analysis suggests that land use 
perturbations may control where some of the dust sources are, but that meteorological variability controls the temporal variability over the last 30 years. However, the potential biases of the visibility dataset prevent strong conclusions based solely on these results.

Acknowledgements. The authors thank A. Dai, C. Zender and P. Rasch for datasets used in this analysis. We would like to thank the AERONET, TOMS AAI and TOMS AOD principal investigators for making available data. We would like to thank C. Zender, R. Miller, S. Engelstaedter and I Tegen for comments on the text.

Edited by: F. J. Dentener

\section{References}

Baker, J., Southhard, R., and Mitchell, J.: Agricultural dust production in standard and conservation tillage systems in the San Joaquin Valley, J. Environ. Qual., 34, 1260-1269, 2006.

Baker, J., Ballantine, J.-A. C., Okin, G. S., Prentiss, D. E., and Roberts, D. A.: Mapping landforms in North Africa using continental scale unmixing of MODIS imagery, Rem. Sens. Environ., 97, 470-483, 2005.

Bonan, G., Levis, S., Kergoat, L., and Oleson, K.: Landscapes as patches of plant functional types: An integrating concept for climate and ecosystem models, Global Biogeochem. Cy., 16, 5.1$5.23,2002$.

Chen, M., Xie, P., Janowiak, J., and Arkin, P.: Global land precipitation: a 50-year monthly analysis based on gauge observations, J. Hydrometeorol., 3, 249-266, 2002.

Chiapello, I., Moulin, C., and Prospero, J.: Understanding the long-term variability of African dust transport across the Atlantic as recorrded in both Barbados surface concentrations and large scales TOMS optical thicknesses, J. Geophys. Res., 110, D18S10, doi:10.1029/2004JD005132, 2005.

Dai, A., Fung, I. Y., and Del Genio, A. D.: Surface observed global land precipitation variations during 1900-88, J. Climate, 10, 2943-2962, 1997.

Dai, A., Trenberth, K. E., and Karl, T. R.: Global Variations in Droughts and Wet Spells, Geophys. Res. Lett., 25, 3367-3370, 1998.

Dai, A., Trenberth, K., and Qian, T.: A global dataset of Palmer Drought Severity Index for 1870-2002: Relationship with soil moisture and the effects of surface warming, J. Hydrometeorol., 5, 1117-1130, 2004

DeMott, P., Sassen, K., Poellot, M., et al.: African dust aerosols as atmospheric ice nuclei, Geophys. Res. Lett., 30, 1732, doi:10.1029/2003GL017410, 2003.

Dentener, F. J., Carmichael, G. R., Zhang, Y., Lelieveld, J., and Crutzen, P. J.: Role of mineral aerosol as a reactive surface in the global troposphere, J. Geophys. Res., 101, 22 869-22 889, 1996.

Engelstaedter, S., Kohfeld, K. E., Tegen, I., and Harrison, S. P.: Controls of dust emissions by vegetation and topographic depressions: An evaluation using dust storm frequency data, Geophys. Res. Lett., 30, 1294, doi:10.1029/2002GL016471, 2003.

Gillette, D. A.: Threshold friction velocities for dust production for agricultural soils, J. Geophys. Res., 93, 12 645-12 662, 1988.
Ginoux, P. Chin, M., Tegen, I., et al.: Sources and distribution of dust aerosols with the GOCART model, J. Geophys. Res., 106, 20 255-20 273, 2001.

Godish, T.: Air Quality. CRC Press, Boca Raton, Florida, 1997.

Goudie, A. and Middleton, N.: Saharan dust storms: nature and consequences, Earth-Sci. Rev., 56, 179-204, 2001.

Goudie, A. S. and Middleton, N. J.: The Changing Frequency of Dust Storms Through Time, Climatic Change, 20, 197-225, 1992.

Grini, A. and Zender, C.: Roles of saltation, sandblasting, and wind speed variability on mineral dust aerosol size distribution during the Puerto Rican Dust Experiment (PRIDE), J. Geophys. Res., 109, D07202, doi:10.1029/2003JD004233, 2004.

Holben, B. N., Eck, T., Slutsker, I., et al.: AERONET-A Federated Instrument Network and Data Archeive for Aerosol Characterization, 2000

Holben, B. N., Tanre, D., Smirnov, A. et al.: An emerging ground-based aerosol climatology:Aerosol optical depth from AERONET, J. Geophys. Res., 106, 12 067-12 097, 2001.

Hurrell, J. W.: Decadal Trends in the North Atlantic Oscillation Regional Temperatures and Precipitation, Science, 269, 676-679, 1995.

Jickells, T., An, Z., Anderson, K., et al.: Global iron connections between dust, ocean biogeochemistry and climate, Science, 308 , 67-71, 2005.

Kistler, R., Kalnay, E., Collins, W., et al.: The NCEP-NCAR 50Year Reanalysis: Monthly Means CD-ROM and Documentation, B. Am. Meteorol. Soc., 82, 247-267, 2001.

Klein-Goldewijk, K.: Estimating global land use change over the past 300 years: the HYDE database, Global Biogeochem. Cy., 15, 417-434, 2001.

Kurosaki, Y. and Mikami, M.: Recent frequent dust events and their relation to surface wind in East Asia, Geophys. Res. Lett., 30, 1736, doi:10.1029/2003GL017261, 2003.

Laurent, B., Maricorena, B., Bergametti, G., Chazette, P., Maignan, F., and Schmetig, C.: Simulation of the mineral dust emission frequencies from desert areas of China and Mongolia using an aerodynamic roughness length map derived from the POLDER/ADEOS 1 surface products, J. Geophys. Res., 110, D18S04, doi:10.1029/2004JD005013, 2005.

Liu, X., Yin, Z.-Y., Zhang, X., and Yang, X.: Analyses of the spring dust storm frequency of northern China in relation to antecedent and concurrent wind, precipitation, vegetation and soil moisture conditions, J. Geophys. Res., 109, D16210, doi:10.1029/2004JD004615, 2004.

Luo, C., Mahowald, N., and Corral, J. D.: Sensitivity study of meteorological parameters on mineral aerosol mobilization, transport and idstribution, J. Geophys. Res., 108, 4447, doi:10.1029/2003JD0003483, 2003.

Mahowald, N., Baker, A., Bergametti, G., et al.: The atmospheric global dust cycle and iron inputs to the ocean, Global Biogeochem. Cy., 19, GB4025, doi:10.1029/2004GB002402, 2005.

Mahowald, N., Bryant, R., Corral, J. D., and Steinberger, L.: Ephemeral lakes and desert dust sources, Geophys. Res. Lett., 30, 1074, doi:10.1029/2002GL016041, 2003a.

Mahowald, N., Muhs, D., Levis, S., et al.: Change in atmospheric mineral aerosols in response to climate: last glacial period, preindustrial, modern and doubled-carbon dioxide climates, J. Geophys. Res., 111, D10202, doi:10.1029/2005JD006653, 2006. 
Mahowald, N. and Dufresne, J.-L.: Sensitivity of TOMS aerosol index to boundary layer height: implications for detection of mineral aerosol sources, Geophys. Res. Lett., 31, L03103, doi:10.1029/2003GL018865, 2004.

Mahowald, N., Luo, C., Corral, J. D., and Zender, C.: Interannual variability in atmospheric mineral aerosols from a 22-year model simulation and observational data, J. Geophys. Res., 108, 4352, doi:10.1029/2002JD002821, 2003b.

Mahowald, N., Rasch, P., Eaton, B., Whittlestone, S., and Prinn, R.: Transport of 222radon to the remote troposphere using the Model of Atmospheric Transport and Chemistry and assimilated winds from ECMWF and the National Center for Environmental Prediction/NCAR, J. Geophys. Res., 102, 28 139-28 151, 1997.

Mahowald, N., Rivera, G., and Luo, C.: Comment on "Relative importance of climate and land use in determining present and future global soil dust emission", Geophys. Res. Lett., 31, L24105, doi:10.1029/2004GL021272, 2004.

Mahowald, N., Zender, C., Luo, C., et al.: Understanding the 30-year Barbados desert dust record, J. Geophys. Res., 4561, doi:10.129/2002JD002097, 2002.

Mahowald, N. M. and Luo, C.: A less dusty future?, Geophys. Res. Lett., 30, 1903, doi:10.1029/2003GRL017880, 2003.

N-Tchayi Mbourou, G., Bertrand, J. J., and Nicholson, S. E.: The Diurnal and Seasonal Cycles of Wind-Borne Dust over Africa North of the Equator, J. Appl. Meteorol., 36, 868-882, 1997.

McTainsh, G. H., Burgess, R., and Pitblado, J. R.: Aridity, drought and dust storms in Australia, J. Arid Environ., 16, 11-22, 1989.

Middleton, N. and Thomas, D. (Eds.): World Atlas of Desertification, Arnold, London, 182 pp., 1997.

Middleton, N. J.: Dust Storms in the Middle East, J. Geophys. Res., 16, 11-22, 1984.

Middleton, P., Stewart, T. R., and Leary, J.: On the Use of Human Judgment and Physical/Chemical Measurements in Visual Air Quality Management, J. Air Pollut. Control Assoc., 35, 11$18,1985$.

Miller, R. and Tegen, I.: Climate Response to Soil Dust Aerosols, Am. Meteorl. Soc., 11, 3247-3267, 1998.

Moulin, C., Lambert, C., Dulac, F., et al.: Long-term daily monitoring of Saharan dust load over ocean using Meteosat ISCCP-B2 data 2. Accuracy of the method and validation using Sun photometer measurements, J. Geophys. Res., 102, 16959-16969, 1997a.

Moulin, C. and Chiapello, I.: Evidence of the control of summer atmospheric transport of African dust over the Atlantic by Sahel sources from TMS satellites (1979-2000), Geophys. Res. Lett., 31, L02107, doi:10.1029/2003GL018931, 2004.

Moulin, C., Lambert, C. E., Dulac, F., and Dayan, U.: Control of atmospheric export of dust from North Africa by the North Atlantic Oscillation, Nature, 387, 691-694, 1997b.

Neff, J., Reynolds, R., Belnap, J., and Lamothe, P.: Multi-decadal impacts of grazing on soil physical and biogeochemical properties in southeast Utah, Ecol. Appl., 15, 87-95, 2005.

Okin, G. S. and Reheis, M.: An ENSO predictor of wind erosion and dust emission in the Southwestern United States, Geophys. Res. Lett., 29, 1332 ,doi:10.1029/2001GL014494, 2002.

Petit, J. R., Jouzel, J., Raynaud, D., et al.: Climate and atmospheric history of hte past 420,000 years from teh Vostok Ice core, Antarctica, Nature, 399, 429-436, 1999.

Prospero, J. and Lamb, P.: African droughts and dust transport to the Caribbean: climate change implications, Science, 302, 10241027, 2003.

Prospero, J., Ginoux, P., Torres, O., and Nicholson, S. E.: Environmental Characterization of Global sources of atmospheric soil dust derived from the NIMBUS-7 TOMS absorbing aerosol product, Rev. Geophys., 40, 1002, doi:10.1029/2000RG000095, 2002.

Prospero, J. M. and Nees, R. T.: Impact of the North African drought and El Niño on mineral dust in the Barbados trade winds, Nature, 320, 735-738, 1986.

Ramankutty, N. and Foley, J.: Estimating historical changes in global land cover: croplands from 1700 to 1992, Global Biogeochem. Cy., 13, 997-1027, 1999.

Rasch, P. J., Collins, W., and Eaton, B. E.: Understanding the Indian ocean Experiment (INDOEX) aerosol distributions with an aerosol assimilation, J. Geophys. Res., 106, 7337-7355, 2001.

Rasch, P. J., Mahowald, N. M., and Eaton, B. E.: Representations of transport, convection and the hydrologic cycle in chemical transport models: Implications for the modeling of short-lived and soluble species, J. Geophys. Res., 102, 18 127-28 138, 1997.

Rosenfeld, D. and Nirel, R.: Seeding effectiveness-the interaction of desert dust and the southern margins of rain cloud systems in Isreal, J. Appl. Meteorol., 35, 1502-1509, 1996.

Seinfeld, J. and Pandis, S.: Atmospheric Chemistry and Physics. John Wiley and Sons, Inc, New York, 1326 pp., 1998.

Smith, S., Huxman, T., Zitzer, S., et al.: Elevated CO2 increases productivity and invasive species success in an arid ecosystem, Nature, 408, 79-82, 2000.

Sun, J., Zhang, M., and Liu, T.: Spatial and temporal characteristics of dust storms in China and its surrounding regions, 19601999:Relations to source area and climate, J. Geophys. Res., 106, 10325-10333, 2001.

Torres, O., Bhartia, P., Herman, J., et al.: A long-term record of aerosol optical depth from TOMS observations andn comparison to AERONET measurements, J. Atmos. Sci., 59, 398-431, 2002.

Torres, O., Bhartia, P. K., Herman, J. R., Ahmad, Z., and Gleason, J.: Derivation of aerosol properties from satellite measurements of backscattered ultraviolet radiation: Theoretical basis, J. Geophys. Res., 103, 17 099-17 110, 1998.

Trenberth, K. E. and Stepaniak, D. P.: Letters: indices of El Nino Evolution, J. Climate, 14, 1697-1701, 2001.

Zender, C., Bian, H., and Newman, D.: Mineral Dust Entrainment and Deposition (DEAD) model: Description and 1990s dust climatology, J. Geophys. Res., 108, 4416, doi:10.1029/2002JD002775, 2003a.

Zender, C. and Kwon, E., Regional contrasts in dust emission responses to climate, J. Geophys. Res., 110, D13201, doi:10.1029/2004JD005501, 2005.

Zender, C., Newman, D., and Torres, O.: Spatial Heterogeneity in Aerolian Erodibility: Uniform, Topographic, Geomorphic and Hydrologic Hypotheses, J. Geophys. Res., 108, 4543, doi:10.1029/2002JD003039, 2003b.

Zhang, X. Y., Gong, S., Zhao, T., et al.: Sources of Asian dust and role of climate change versus desertification in Asian dust emission, Geophys. Res. Lett., 30, 2272, doi:10.1029/2003GL018206, 2003.

Zhao, C., Dabu, X., and Li, Y.: Relationship between climate factors and dust storm frequency in Inner Mongolia of China, Geophys. Res. Lett., 31, L01103, doi:10.1029/2003GL018351, 2004. 
N. M. Mahowald et al.: Global trends in visibility: implications for dust sources

Zijiang, Z. and Guocai, Z.: Typical severe dust storms in northern China during 1954-2002, Chinese Sci. Bull., 48, 2366-2370, 2003. 